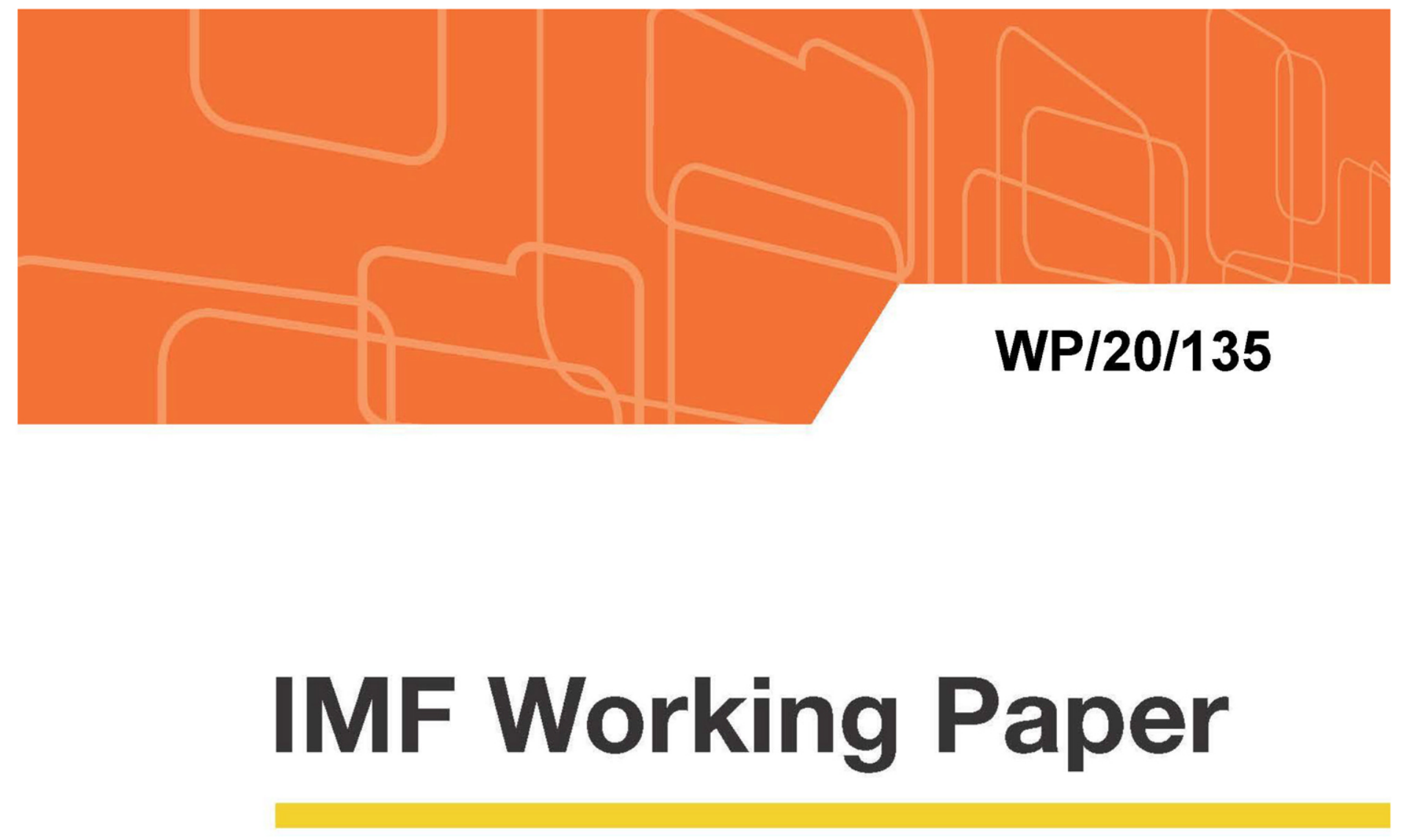

\title{
Harnessing Digital Technologies to Promote SMEs and Inclusive Growth in the MENAP Region
}

by Inutu Lukonga

IMF Working Papers describe research in progress by the author(s) and are published to elicit comments and to encourage debate. The views expressed in IMF Working Papers are those of the author(s) and do not necessarily represent the views of the IMF, its Executive Board, or IMF management.

$$
\text { I N T E R N A T I O N A L M O N E T A R Y F U N D }
$$




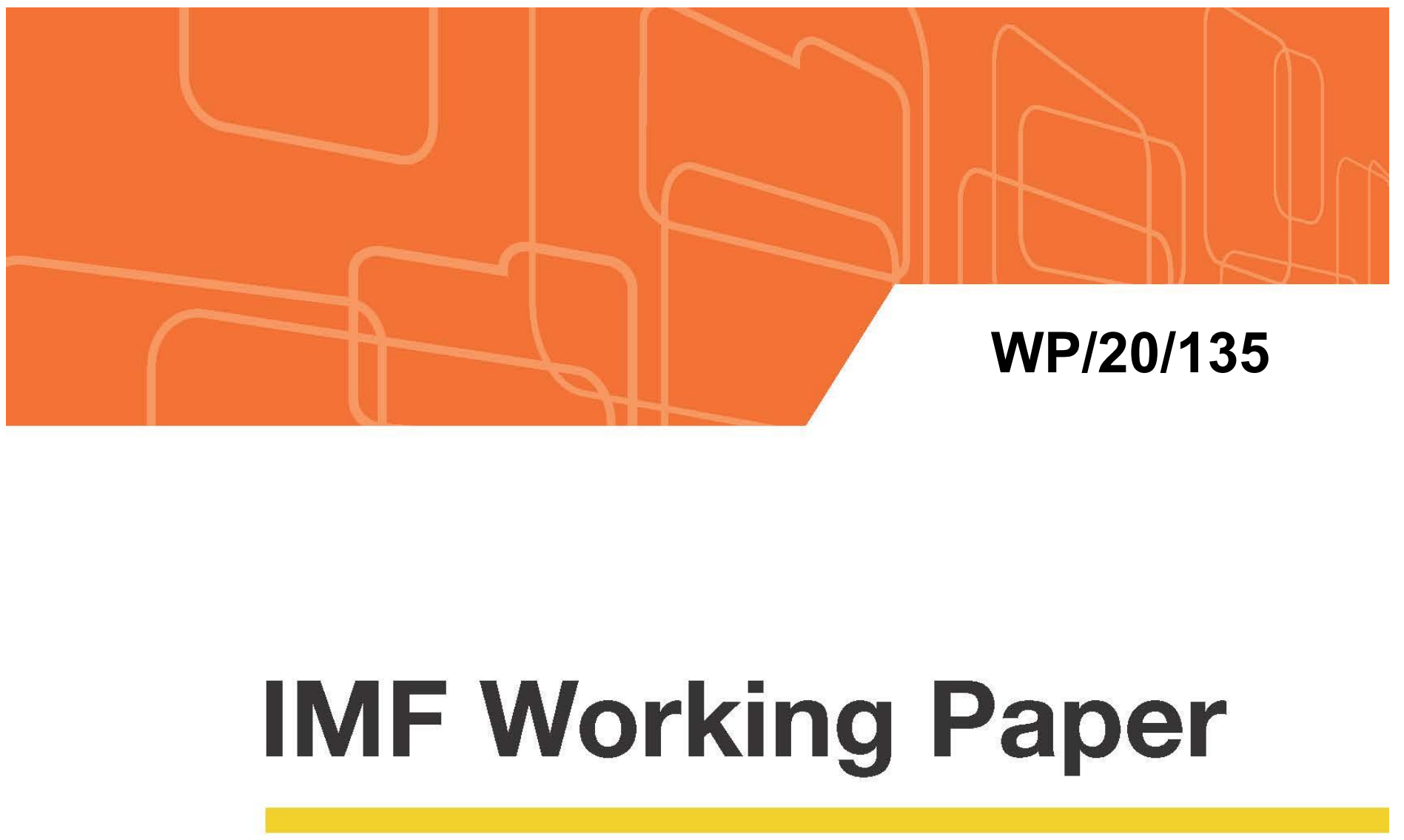

\section{Harnessing Digital Technologies to Promote SMEs and Inclusive Growth in the MENAP Region}

by Inutu Lukonga

IMF Working Papers describe research in progress by the author(s) and are published to elicit comments and to encourage debate. The views expressed in IMF Working Papers are those of the author(s) and do not necessarily represent the views of the IMF, its Executive Board, or IMF management.

$$
\text { I N T E R N A T | O N A L M O N E T A R Y F U N D }
$$




\title{
IMF Working Paper
}

Middle East and Central Asia Department

\section{Harnessing Digital Technologies to Promote SMEs and Inclusive Growth in the Middle East, North Africa, Afghanistan and Pakistan (MENAP) Region}

\section{Prepared by Inutu Lukonga}

Authorized for distribution by Bikas Joshi

July 2020

IMF Working Papers describe research in progress by the author(s) and are published to elicit comments and to encourage debate. The views expressed in IMF Working Papers are those of the author(s) and do not necessarily represent the views of the IMF, its Executive Board, or IMF management.

\begin{abstract}
Policy makers in the MENAP region have been formulating policies and designing programs to develop small and medium sized enterprises (SMEs) with a view to create jobs and achieve inclusive growth. But while the programs have helped increase the number of enterprises, growth of SMEs continues to face barriers to growth. As a result, microenterprises predominate and SMEs contribution to employment remains below potential. Partial implementation of reforms explain some of the underperformance, but frictions in strategy design also played an important role. Sustaining current reforms is, therefore, not sufficient to achieve inclusive growth. Digital technologies have potential to boost SMEs productivity and growth and economies are rapidly digitalizing, thus SMEs need to embrace digital solutions to compete and survive. Therefore, for SMEs to be effective engines of inclusive growth, a rethinking of the SME development strategy is needed that makes SMEs' digital transformation a priority.
\end{abstract}

JEL Classification Numbers: 053, 033, 031, L25, G24, G28, G53, G38, K24

Keywords: Digitalization, Digital Technologies, Inclusive Growth, MENAP Region.

Author’s E-Mail Address: ilukonga@imf.org 


\section{Table of Contents}

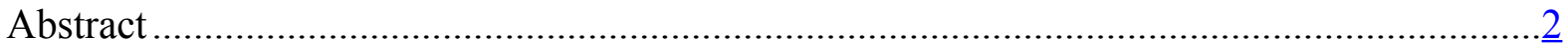

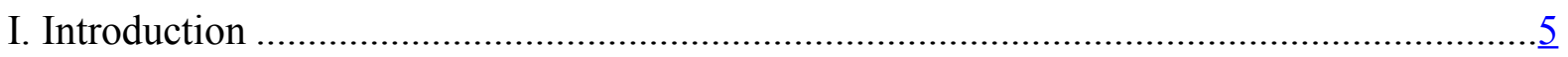

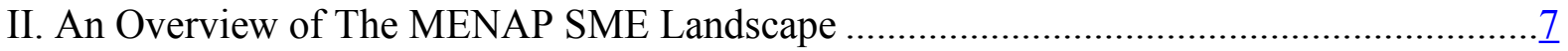

A. Structure of MENAP SMEs, Performance and Constraints to Growth ............................. 7

B. Policies and Programs to Promote SMEs.................................................................11

C. Evaluation of the Effectiveness of Support Policies for SMEs.......................................15

III. Digitalization of SMEs in MENAP — Overview, Opportunities and Trends....................20

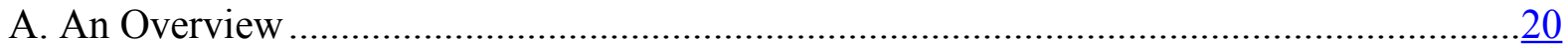

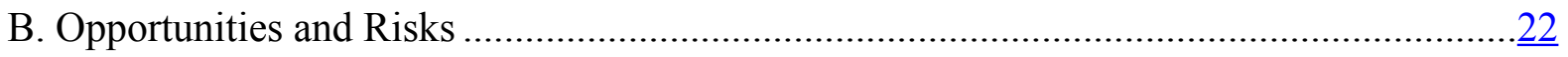

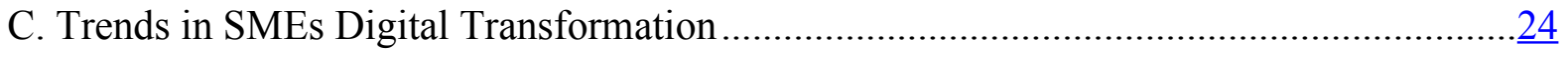

D. The Digital Landscape and Constraints to SMEs' Digitalization ................................... 27

IV. Policy Options to Promote SMEs and Inclusive Growth in MENAP ............................39

A. An Enabling Environment for Digitalization of SMEs.............................................. $\frac{39}{42}$

B. Financial Sector and Business Environment Reforms ................................................ 42

Figures

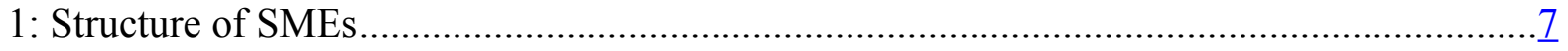

2. Composition of SMEs by Business Sector and Markets ................................................... $\underline{8}$

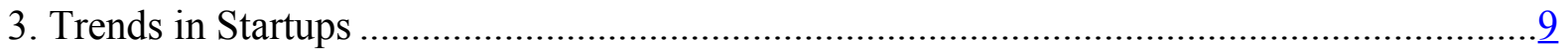

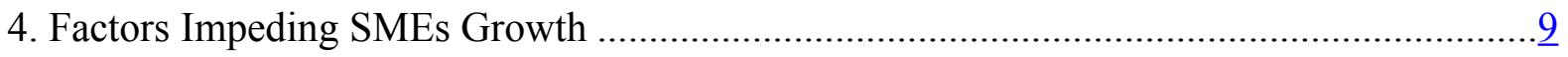

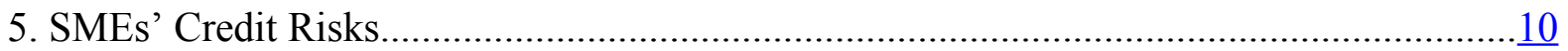

6. Initiatives to Enhance SMEs' access to Finance..............................................................12

7. Policy Reforms to Ease the Process of Establishing Businesses ....................................13

8. Business Support Programs .................................................................................. 14

9. Performance of SMEs .......................................................................................... 15

10. Factors Underpinning SMEs performance.............................................................16

11. Selected Factors Impeding SMEs’ Access to Bank Finance ........................................17

12. Factors Constraining Funding from Non-Bank Financial Institutions ...........................18

13. Business Environment for Starting and Operating a Business ......................................19

14. Pillars of a Digital Ecosystem for Enterprises ........................................................22

15. Trends in Internet Adoption and Business Digitalization...........................................

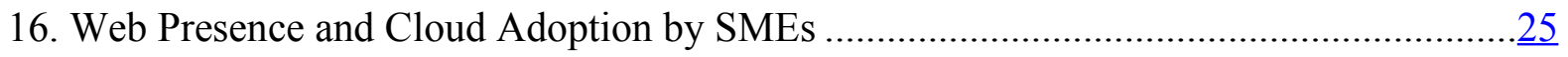

17. E-Commerce Trends ........................................................................................26

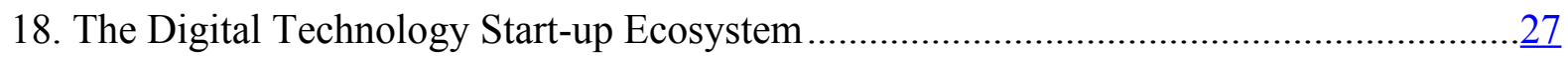

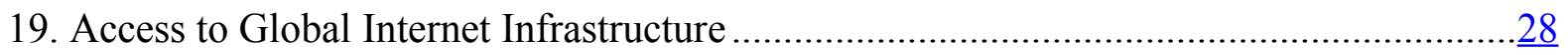

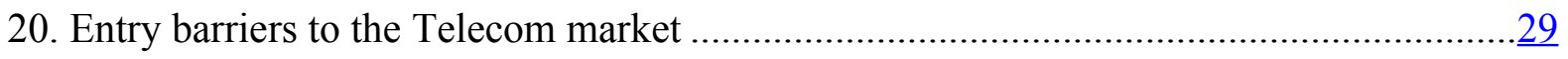

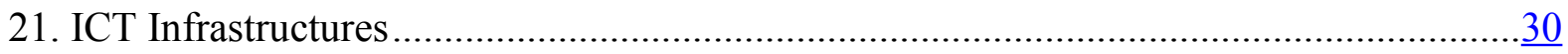

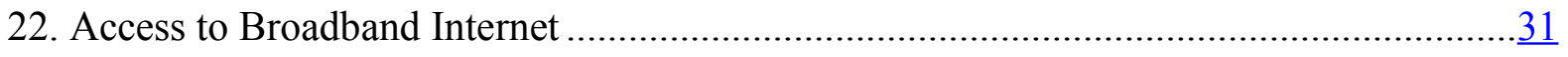


23. Internet Speed $\underline{32}$

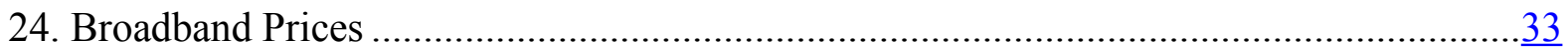

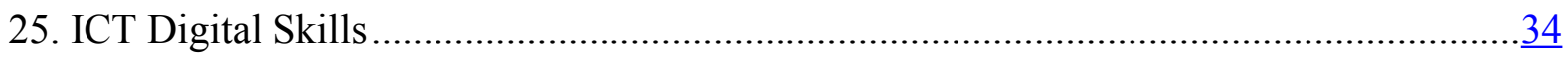

26. Digital Payment Infrastructure and Financial Services ..................................................

27. Factors Constraining E-Commerce Development …………………..........................

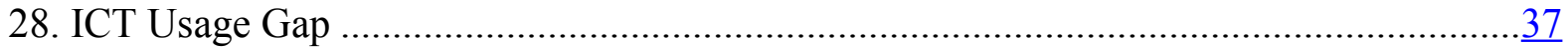

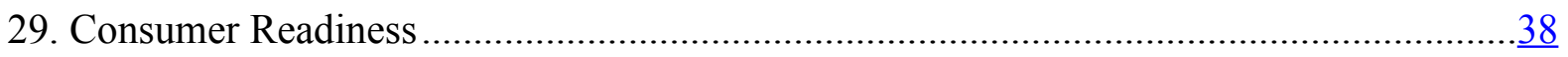

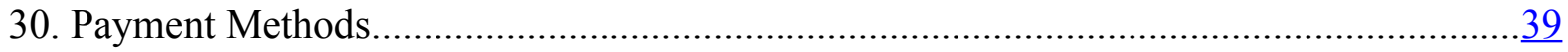

Appendices

1. Digital Technologies and the Potential Benefits they Present $\underline{44}$

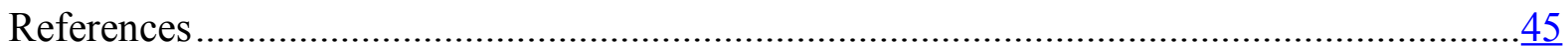




\section{INTRODUCTION}

Development of micro, small and medium-sized enterprises (SMEs) has become the centerpiece of strategies to achieve inclusive growth in the Middle East, North Africa, Afghanistan and Pakistan (MENAP) region. Countries across the region, in varying degrees, face high youth unemployment rates, declining capacity of the public sector to absorb new labor entrants, lower and volatile oil prices, and widening income disparities. Against this backdrop, policymakers have been designing strategies to catalyze the growth of SMEs and startups with a view to create jobs and ensure that growth is inclusive. In commodity dependent economies, development of SMEs is being pursued to help diversify economies.

Strategies to promote the development of SMEs in MENAP have sought to be comprehensive by easing barriers to entry, growth and exit of businesses. To facilitate entry, many countries tried to improve the business climate by reducing the time and costs of starting businesses, including through the establishment of one stop shops and online platforms as well as reducing capital requirements (World Bank 2019). To promote the growth of the SME sector, policy makers created incentives to enhance access to finance by creating incentives for banks to lend to SMEs and to develop non-bank funding sources. Several countries modernized their insolvency regimes to facilitate corporate restructuring and provide legal certainty to lenders regarding enforceability of their claims in bankruptcy. More recently, there has been a push to promote innovation and entrepreneurship and to establish dedicated institutions for the development of SMEs.

But despite the multitude of incentives, SMEs in MENAP continue to face barriers to growth, and their contribution to employment trails other regions. SMEs continue to experience challenges accessing finance and the business and regulatory environment has not been sufficiently enabling. The enterprises also face internal constraints related to talent gaps and weak managerial capacities (Saleem 2017). These constraints are manifesting in a concentration of SMEs in activities that require low resources, in terms of capital, skills and financing and in the predominance of microenterprises that generate limited employment opportunities, are low paying and low value adding. Educated youths, therefore, prefer to take up jobs in the public sector and large corporations that offer better salaries and benefits.

The COVID-19 pandemic has added to the challenges that SMEs in MENAP face and threatens to accentuate already elevated levels of unemployment in the region. The sectors in which the SMEs are concentrated are also the ones that have been badly hit by measures to contain the spread of the virus - such as trade, tourism, and transportation. As most SMEs have also not digitalized their business model, the "great lockdown" has brought operations of many SMEs to a sudden standstill. With microenterprises predominating the SME sector,

The author would like to thank Oluremi Akin-Olugbade, Kate Nguyen, Gohar Abajyan, Tatiana Pecherkina for technical support, and Mwanza Nkusu, Debbie Chungu, Herve Tourpe, Nadine Schwarz, Ender Emre, Masaru Itatani, David Rozumek and Heedon Kang (IMF) for the insightful and helpful comments on the draft. The report also benefited from discussions with Natalija Gelvanovska-Garcia, Rogy Michel and Carlo Maria Rossotto as well as participants in the MENA seminar series (World Bank). 
the level of cashflows are unlikely to withstand substantial periods of business disruptions. In addition, since SMEs are the predominant form of business in MENAP and significant contributors to employment, a weakening of the SMEs productive capacity has potential to significantly increase unemployment.

For SMEs to be the engines of inclusive growth, a re-thinking of SME development strategies is needed that puts digitalization at the center of reforms. ${ }^{2}$ Empirical studies show that technology can enhance operational efficiencies, innovation, access to international markets and overall productivity, thereby promote enterprise growth (Accenture 2016, OECD 2017, WTO 2019). Digital innovations can also help unlock funding for SMEs, improve government efficiencies and integrate women in the labor force. The "great lockdown" has demonstrated how digital technologies can facilitate business continuity and enhance resilience to shocks. But more critical, digital technologies are rapidly transforming consumer expectations, thus SMEs need to adapt to remain competitive in the digital economy.

This study aims to identify the policy mix that can enable MENAP SMEs to leverage digital technologies to boost growth and promote inclusive growth. The analysis addresses four principal questions:

- Why did strategies to promote the development of SMEs in MENAP have a limited impact on their growth and employment creation in the region?

- Can digital technologies usher in a new era of resilience, growth and quality employment generation among SMEs?

- How digitalized are MENAP SMEs and what constraints do they face in digitalizing their businesses?

- What policy mix can enable SMEs to leverage digital technologies to boost their growth and achieve inclusive growth, and what role should the government play?

The study applies benchmarking techniques and gap analysis to assess the performance of MENAP SMEs and identify needed policies. The review covers 21 of the 24 countries that make up the MENAP region. ${ }^{3}$ Data on SME demographics for MENAP countries are currently scanty and do not permit econometric testing of the causes of SMEs' underperformance, thus the assessment of the impact of policies implemented to promote SMEs is largely qualitative. The analysis is based on both primary and secondary data sources from central bank reports, presentations by senior government officials, World Bank

\footnotetext{
${ }^{2}$ Digitalization is the use of data, digital technologies and interconnections to create business or change existing activities.

${ }^{3}$ The three countries not covered include Syria, Libya and West Bank and Gaza (WBG).
} 
enterprise surveys and other studies, as well as information obtained through seminars at the IMF, World Bank and regional bodies in the MENA region.

The study is organized as follows: Section II provides an overview of the landscape for SMEs in MENAP, covering their structure, performance and impediments to growth. This section also reviews the policies that have been implemented by various countries to promote SMEs growth and evaluates their effectiveness. Section III discusses the benefits of SMEs adopting digital technologies, analyses digitalization trends in MENAP SMEs, and identifies factors hampering the digital transformation of SMEs. Section IV summarizes the findings and identifies policy strategies to enable SMEs to leverage digital technologies to boost their growth and employment creation, thereby facilitate inclusive growth.

\section{AN OVERVIEW OF THE MENAP SME LANDSCAPE}

\section{A. Structure of MENAP SMEs, Performance and Constraints to Growth}

As with other regions, SMEs are the predominant form of businesses in MENAP and are significant contributors to GDP and employment. SMEs, on average, account for over 90 percent of total businesses (Figure 1). The share of employment accounted for by SMEs ranges from the low teens in Algeria to more than 50 percent in several countries (Bahrain, UAE, Iran, Jordan, Lebanon, Egypt, Pakistan, Tunisia) while SMEs' contributions to GDP range from a low of 10 percent in Qatar to more than 70 percent in some of the oil-importing countries (Egypt, Tunisia, Yemen). The significance of SMEs in MENAP economies is even greater when the informal sector is considered (Saleem 2017).

\section{Figure 1: Structure of SMEs}

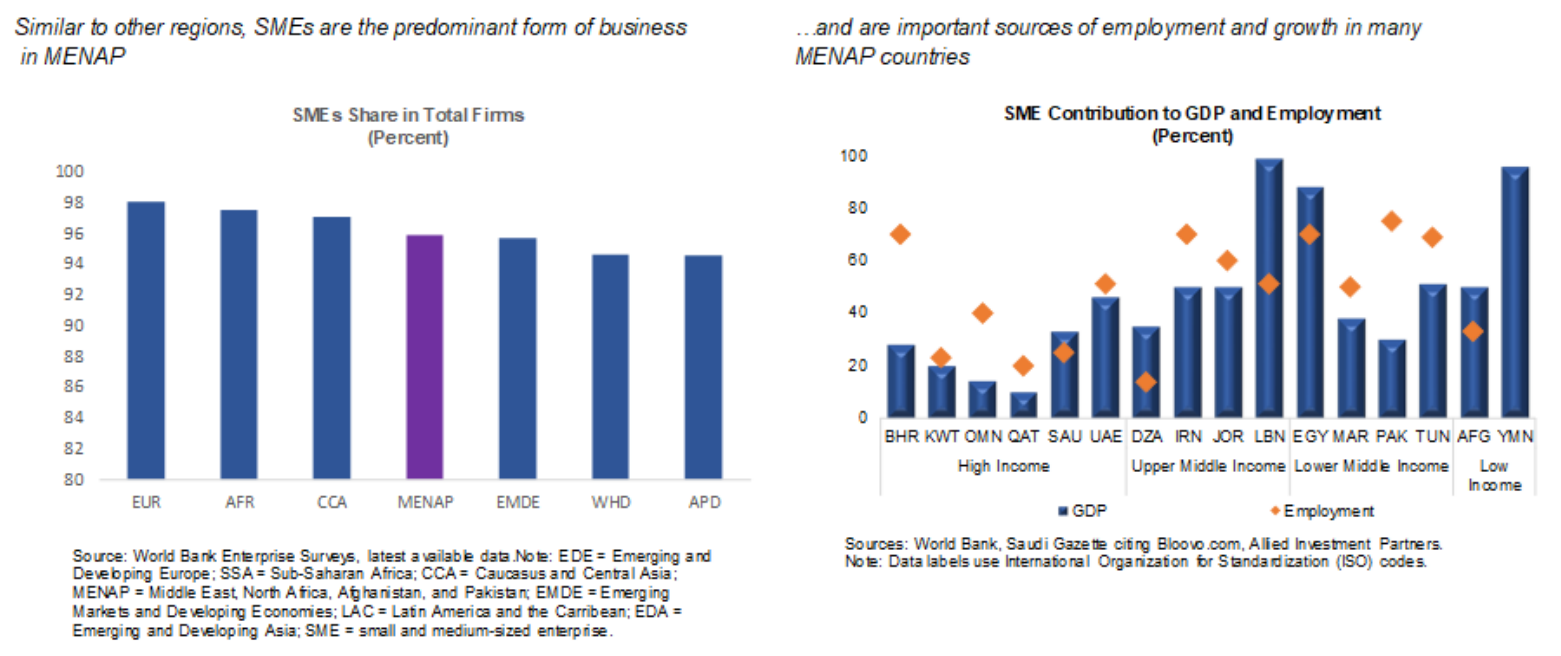


SMEs are a heterogeneous group that operate in a variety of sectors. ${ }^{4}$ The business activities range from single artisans with few or no paid employees to high-growth firms offering innovative goods, services, and business models that target local, national or international markets. In most MENAP countries, SMEs are concentrated in the service sector such as trade, retail distribution, and simple contracting (Figure 2). These sectors are characterized by low entry costs and resource requirements, but they are also low value-adding and low paying. The SMEs mostly focus on the domestic market and participation in global value chains (GVC) is still very low (WTO 2019).

\section{Figure 2. Composition of SMEs by Business Sector and Markets}
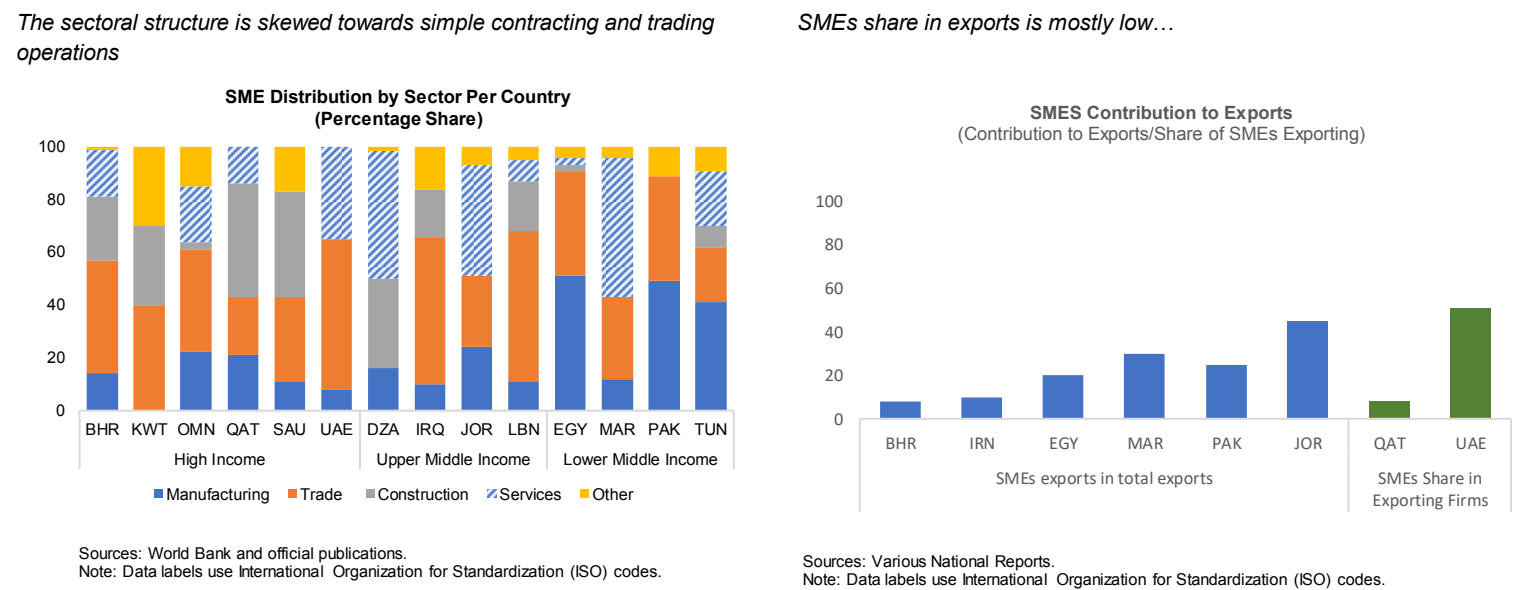

The number and scale of startups is growing rapidly, but activities are concentrated in a few countries. ${ }^{5}$ Investments in startups increased at a compound annual growth rate of 22.5 percent between 2015 and 2019 and the number of startups worth over US\$100 million also increased (Magnit 2019). The activities are, however, geographically concentrated, with eight countries (Bahrain, Egypt, Jordan, Lebanon, Oman, Saudi Arabia, Tunisia, and UAE) accounting for over 85 percent of all startups and the UAE alone accounting for a third of the activities (Figure 3). Developmental strategies that emphasize entrepreneurship, innovation, diversification and increased funding contributed to the rapid growth, while government support and international interest helped actualize the growth. But while the startups are creating employment opportunities, the magnitudes have not been sufficient to significantly reduce unemployment levels among the youth (WAMDA 2016).

\footnotetext{
${ }^{4}$ There is no universally agreed definition of SMEs and many MENAP countries follow more than one definition of SMEs based on the number of employees, turnover, value of sales or assets, though the number of employees is the most commonly applied parameter. SMEs vary in scale and are typically classified into three categories of micro, small and medium.

${ }^{5} \mathrm{~A}$ unicorn is a privately held startup company valued at over $\$ 1$ billion.
} 
Figure 3. Trends in Startups
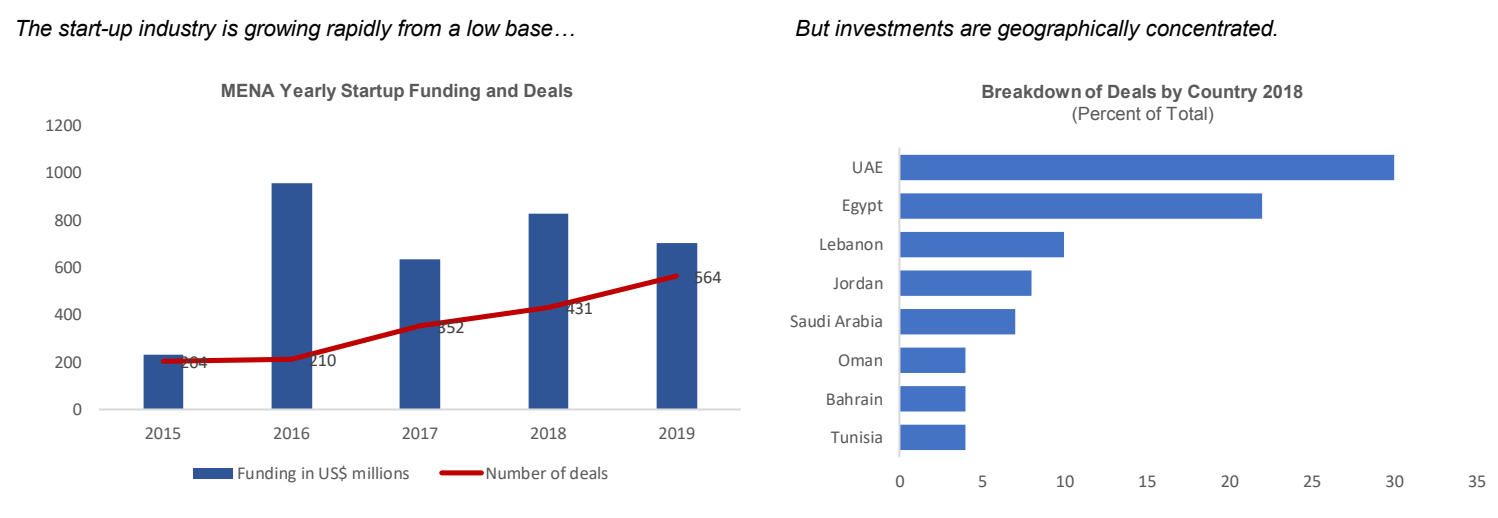

Sources: Magnit

The growth of SMEs and startups in MENAP has been hampered by both external and internal constraints (Figure 4). Limited access to finance is the most commonly cited factor but unfavorable business environments, and talent gaps are also reported to be important. Other constraints tend to be more country specific, including corruption, unreliable supply of electricity, high tax rates, competition from imports, lack of access to public procurement, high interest rates, political instability and informality (Saleem 2017, IFC 2017 and WEF 2016). Factors hampering SMEs access to finance include structural and policy factors coupled with banks and SMEs internal constraints.

\section{Figure 4. Factors Impeding SMEs Growth}
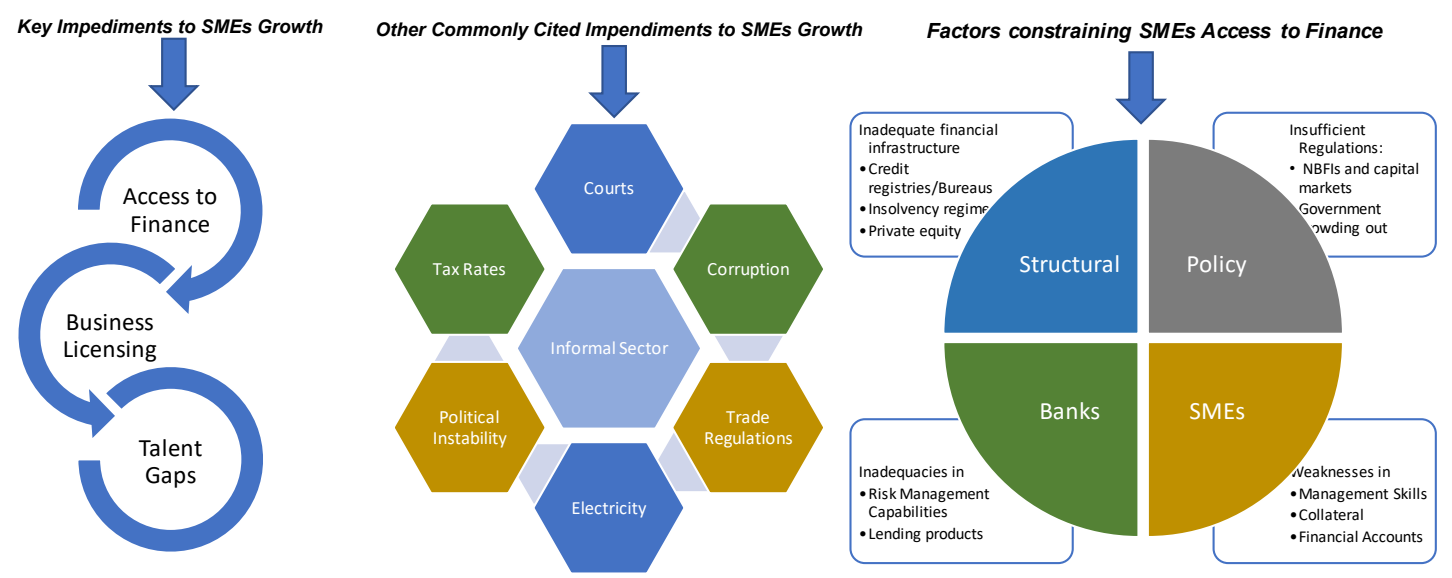

Source: World Bank Enterprise Survey, World Economic Forum (WEF) and Country Reports

- Structural: Limited coverage of credit registries and bureaus result in information asymmetries on borrower creditworthiness. Weak insolvency regimes render it difficult for creditors to enforce claims in bankruptcy and are a factor in banks requiring multiple collaterals. Underdeveloped private equity markets limit availability of funds for start-ups. 
- $\quad$ Policy: Restrictive regulations have impeded the growth of non-bank financial institutions and availability of long-term and equity capital, while excessive government borrowing from domestic banks crowds out the private sector.

- $\quad$ SMEs exhibit high credit risks due, in large part, to weaknesses in management skills, lack of collateral and financial accounts which contribute to banks charging high interest rates and demanding physical or multilateral collateral. ${ }^{6}$

- $\quad$ Banks: Inadequacies in risk management and slow development of suitable lending products limit banks' lending capacity.

SMEs exhibit greater susceptibility to economic shocks due to limited capital buffers, weak governance, and limited digital capabilities. Data on the financial performance of SMEssuch as cashflows, profitability and delinquencies through various economic cycles - are scarce. But cross-country data show a positive correlation, albeit moderate, between the level of the NPL ratio and the exposure of the banking system to SMEs. Non-performing loans (NPL) ratios for SMEs are, in many cases, much higher than the average NPL ratios for the overall banking systems, and nonbank financial institutions (NBFIs) with comparatively large exposures to SMEs exhibit higher levels of NPLs than banks do (Figure 5). The COVID-19 pandemic further unmasked the vulnerabilities from the lack of digital capabilities as the impossibility of working remotely resulted in the lockdown halting business operations of many SMEs.

\section{Figure 5. SMEs' Credit Risks}
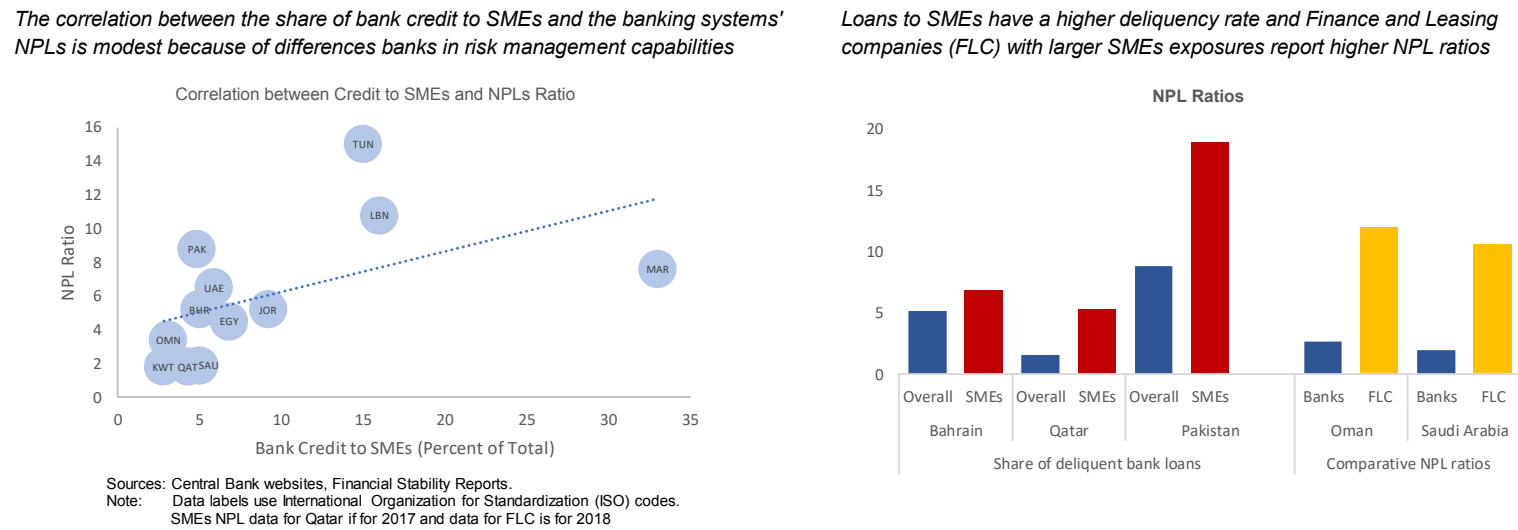

\footnotetext{
${ }^{6}$ Indeed, bank loans have tended to be mostly for short-term requirements and working capital finance, and more conservative banks require a three-year trading history before considering a loan which by design precludes the start-ups.
} 


\section{B. Policies and Programs to Promote SMEs}

As inclusive growth has become a policy priority across the MENAP region, countries have intensified programs to catalyze SME growth. Consistent with deficiencies identified from surveys, SME growth strategies sought to enhance firms' access to finance, improve the business environment, and strengthen the institutional support framework and business development assistance.

\section{Enhancing SMEs Access to Finance}

Enhancing SMEs access to finance has been the focus of most policy initiatives. Figure 6 lists the measures introduced and the countries that introduced them. As financial systems in MENAP are dominated by banks, most reforms were designed to increase bank lending to SMEs. Additionally, some countries tried to broaden funding from non-banks, and a few sought to stimulate SMEs' demand for credit by reducing the cost of funding and easing religious barriers to credit demand.

Multiple strategies were adopted to encourage banks to extend credit to SMEs but the most prevalent are credit guarantees and credit registries. Over 80 percent of countries established credit guarantee schemes to reduce losses to banks in the event that borrowers defaulted as well as established credit registries and/or bureaus to enable banks to make informed assessments about their borrowers' credit risk. Forty percent of the countries modernized insolvency regimes and 20 percent strengthened judiciary systems with a view to provide legal certainty and clarity to lenders regarding enforceability of claims in bankruptcy and to facilitate restructuring of firms. ${ }^{7} \mathrm{~A}$ few countries enacted laws that support pledging moveable collateral and established collateral registries to broaden the range of collateral that SMEs can pledge. A few countries specified the proportion of the banks' lending portfolio to be allocated to SMEs in a bid to compel the banks to increase lending to SMES. ${ }^{8}$

\footnotetext{
${ }^{7}$ For some countries (Bahrain, Egypt, Saudi Arabia, and UAE) insolvency laws were modernized to encourage corporate reorganization over liquidation and boost transparency and efficiency. In varying degrees, the laws expand assets subject to insolvency, give priority to secured creditors inside bankruptcy, allow out of court settlements, allows debtors to initiate reorganization procedure, allow post commencement credit and increase participation of creditors in the insolvency proceedings.

${ }^{8}$ Kuwait gave preferential risk weights for SME loans of 75 percent versus standard 100 percent for other enterprises which were reduced to 25 percent as part of the response to the COVID-19 pandemic. Banks in Egypt were permitted to reduce the level of mandatory reserves held with the CBE by the amount of credit they extend to SMEs.
} 
Figure 6. Initiatives to Enhance SMEs' access to Finance

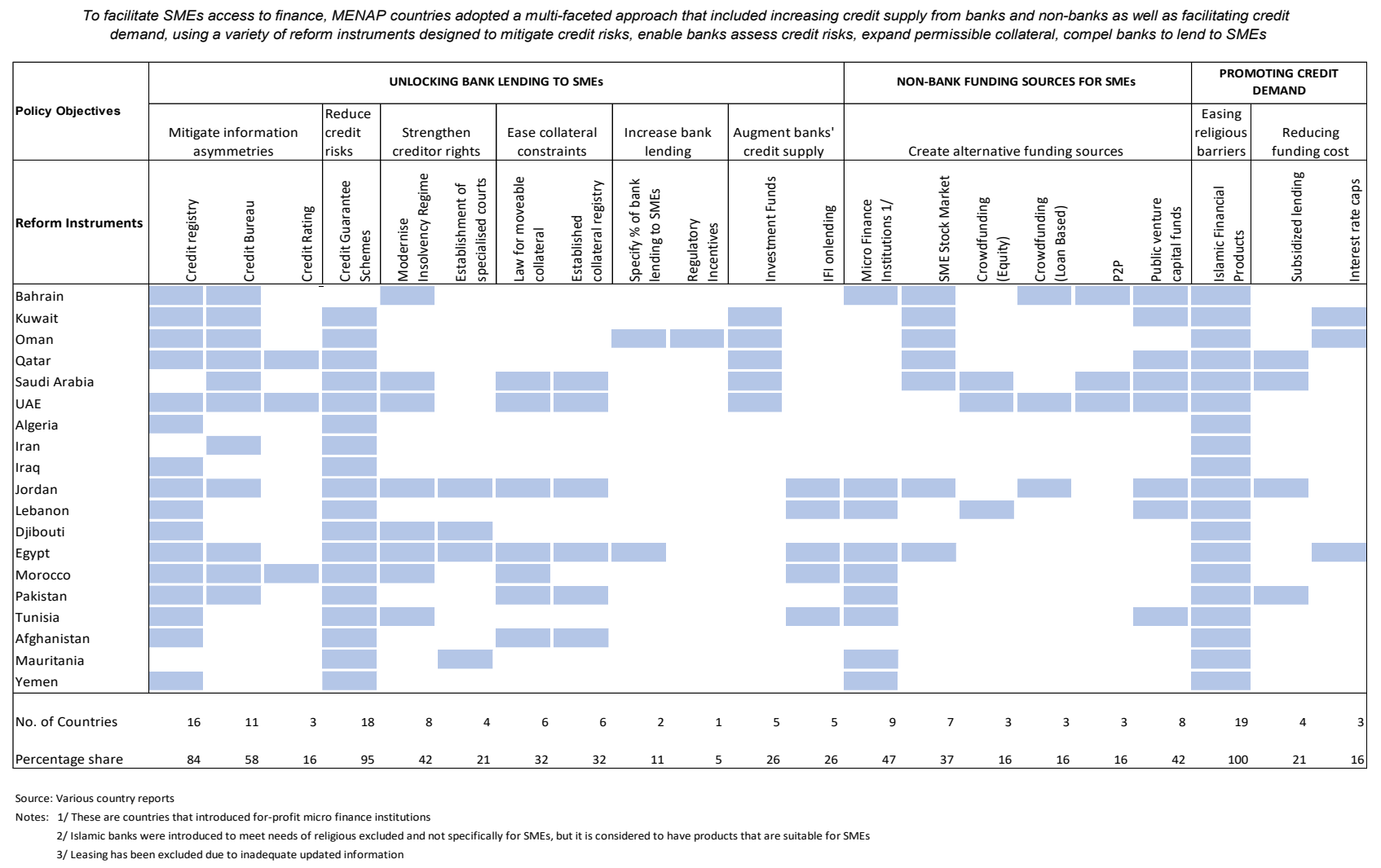

Reforms to develop other segments of financial systems received renewed attention as part of efforts to develop alternative funding sources for SMEs (Figure 6). At least nine countries enacted regulations to establish micro-finance sectors and/or opened the microfinance institutions (MFI) sector to new for-profit players in order to improve the supply environment and competition. ${ }^{9}$ Seven countries introduced alternative equity listings for SMEs on their stock markets that require less stringent disclosure and reporting requirements. A few countries developed SME-focused funds (McKinsey 2018), enacted regulations for $\mathrm{VC}$ and private equity (PE) to set up funds locally and, in some cases, created venture capital funds (VC). ${ }^{10}$ Three countries enacted regulations for equity and debt crowdfunding platforms. A Peer to Peer (P2P) platform established in the UAE has expanded operations to other countries in the region (Bahrain, Saudi Arabia).

\footnotetext{
${ }^{9}$ Several countries (Afghanistan, Algeria, Oman, Egypt, Jordan, Morocco, Pakistan, and Tunisia) developed the leasing industry but the sector has not been covered because of the lack of updated data.

10 The funds have varied in form and scope and include Saudi Arabia's Public Investment Fund to support SMEs by investing in venture capital and private equity funds, Bahrain fintech VC funds, Jordan's Innovative start-up fund, Lebanon central bank start-up fund and Tunisia startup Act.
} 
Policy measures to promote SMEs' demand for credit were less prevalent, but some reforms, indirectly promoted demand. A couple of countries (Kuwait, Egypt) specified caps on the maximum interest rates that banks are permitted to charge on loans to SMEs with a view to ensure that credit to SMEs was affordable. ${ }^{11}$ A few others (Saudi Arabia, Jordan) offer SMEs subsidized interest rates through specialized credit institutions and the central bank, respectively. All countries created an enabling environment for the development of Islamic banks to include clients that are financially excluded on religious grounds with positive spillover effects on SMEs financing since Islamic finance products have characteristics that are suitable for financing SMEs.

\section{Improving the Business Environment ${ }^{12}$}

Making it easier to formally register a business is the area of business regulatory policy that has seen the most attention from MENAP policymakers. In the decade through 2019, many countries introduced one-stop shops to reduce the time and costs of starting businesses for SMEs, built online platforms to streamline registrations and payments, and eliminated or reduced minimum capital requirements (Figure 7).

\section{Figure 7. Policy Reforms to Ease the Process of Establishing Businesses}

Many MENAP countries streamlined the processes for business creation and also reduced costs for starting business

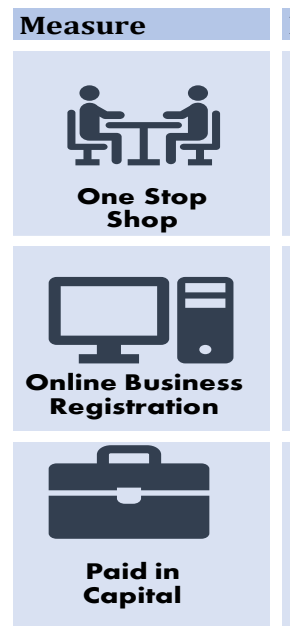

\section{Nature and Objective of the Reforms}

Set up "one-stop shop" service points to streamline the business registration process, thereby lowering the time needed to register a legal business entity.

Introduced on-line services for registering businesses to improve information-sharing across the various government agencies involved, thereby reducing time for business registration.

Eliminated or reduced paid-in minimum capital requirements - the amount that entrepreneurs must legally deposit in a bank or with a notary when incorporating a business.

\section{Countries that implemented reforms}

- Djibout

- Egypt

- Jordan

- Kuwait

- Mauritania

- Morocco

- Oman

- Pakistan

- Saudi Arabia

- Tunisia

- Egypt

- Iran

- Iraq

- Kuwait

- Lebanon

- Morocco

- Oman

- Pakistan

- Saudi Arabia

- Tunisia

- UAE

- Afganistan

- Algeria

- Bahrain

- Djibout

- Egypt

- Jordan

- Kuwait
- Mauritania

- Morocco

- Oman

- Saudi Arabia

- Tunisia

- UAE

- Yemen

Source: World Bank Doing Business, 2019

${ }^{11}$ The Central bank of Egypt (CBE) capped rates for SME lending at ultra-low levels, ranging from 5 percent for small businesses to 12 percent for working capital for mid-sized firms.

${ }^{12}$ Reforms to improve the process of operating and exiting business - dealing with construction permits, getting electricity, registering property, paying taxes, and trading across borders - are not covered in this report. 


\section{Institutional Support Framework for SMEs and Business Support}

Formal SME strategies have gained traction as a tool for ensuring effective and coherent SME policies. Many countries have developed a formal definition of SMEs, an ecosystem of public and semi-public institutions to promote the SME sector, and business support services. Several countries have also issued regulations mandating that specified shares of public procurement programs be allocated to SMEs, provided logistical support to enable SMEs to compete in export markets, and have been supporting local entrepreneurs with business support schemes such as incubators, accelerators, funding agencies, training and targeted initiatives at universities (Figure 8).

\section{Figure 8. Business Support Programs}

\begin{tabular}{|c|c|c|}
\hline NATURE OF CONSTRAINTS FACING SMES & $\begin{array}{l}\text { INITIATIVES TO FACILITATE SMES } \\
\text { ACCESS TO MARKETS }\end{array}$ & $\begin{array}{c}\text { BUSINESS SUPPORT TO SMES AND } \\
\text { STARTUPS }\end{array}$ \\
\hline $\begin{array}{l}\text { Public Sector Markets } \\
\text { - Lack of knowledge about the laws and procedures } \\
\text { governing procurement of government contracts. } \\
\text { - SMEs unaware of opportunities } \\
\text { - Governments requiring large downpayments on } \\
\text { public contracts. } \\
\text { - Lack of transparency in awarding government } \\
\text { contracts. } \\
\text { Export Markets } \\
\text { - Lack of capacities for export process } \\
\text { - Inadequate information about export markets } \\
\text { Limited access to long term funding } \\
\text { Start-Ups } \\
\text { - High upfront costs for starting the business, } \\
\text { including long term leases } \\
\text { - Bureacracy is challenging }\end{array}$ & 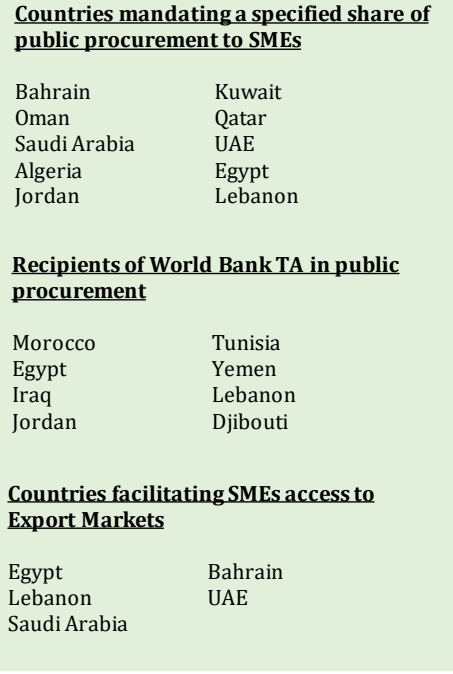 & 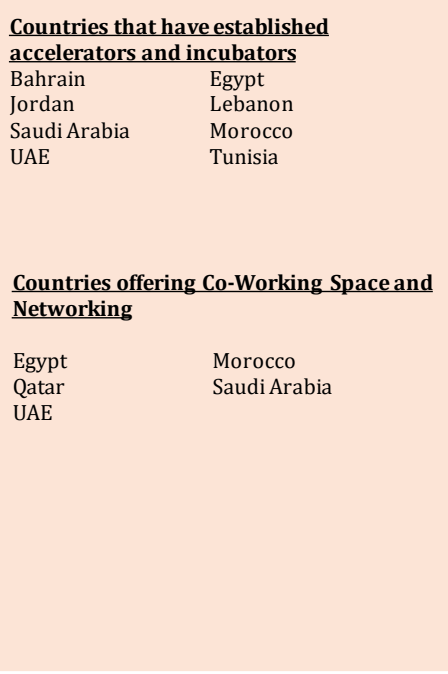 \\
\hline
\end{tabular}

SME development and policies have also been a central area for collaboration with international organizations. The World Bank has provided policy advice, lending services to clients, and technical assistance, including building the capacity of SMEs to enable them to compete in the public procurement market. The European Investment Bank has also been increasing its lending to SMEs in several MENAP countries (Egypt, Jordan, Lebanon, Morocco, and Tunisia), including mobilizing investments through risk-sharing arrangements with local banks to support the SME sector. Under the MENA-OECD competitiveness program, policy support has been provided to countries through analytical work and technical assistance, including capacity building for government officials involved in private sector development and SME policies. 


\section{Evaluation of the Effectiveness of Support Policies for SMEs}

Systematic evaluations of program successes are lacking but, while the policies have had a positive impact, the effects have fallen short of the objectives. Barriers to SME growth persist, including access to finance, unfavorable business and regulatory environments, talent gaps, and weak SME managerial capacities. SME funding gaps and the share of microenterprises in the SME universe is higher than other regions. The programs have facilitated an increase in the number of SMEs, but few have scaled up, and the contribution of SMEs to GDP and employment is modest relative to their weight in the economy and compared to other regions (Figure 9). This underperformance can be attributed to partial implementation of reforms and other idiosyncratic factors, but frictions in the design of the SMEs strategy also played an important role.

\section{Figure 9. Performance of SMEs}
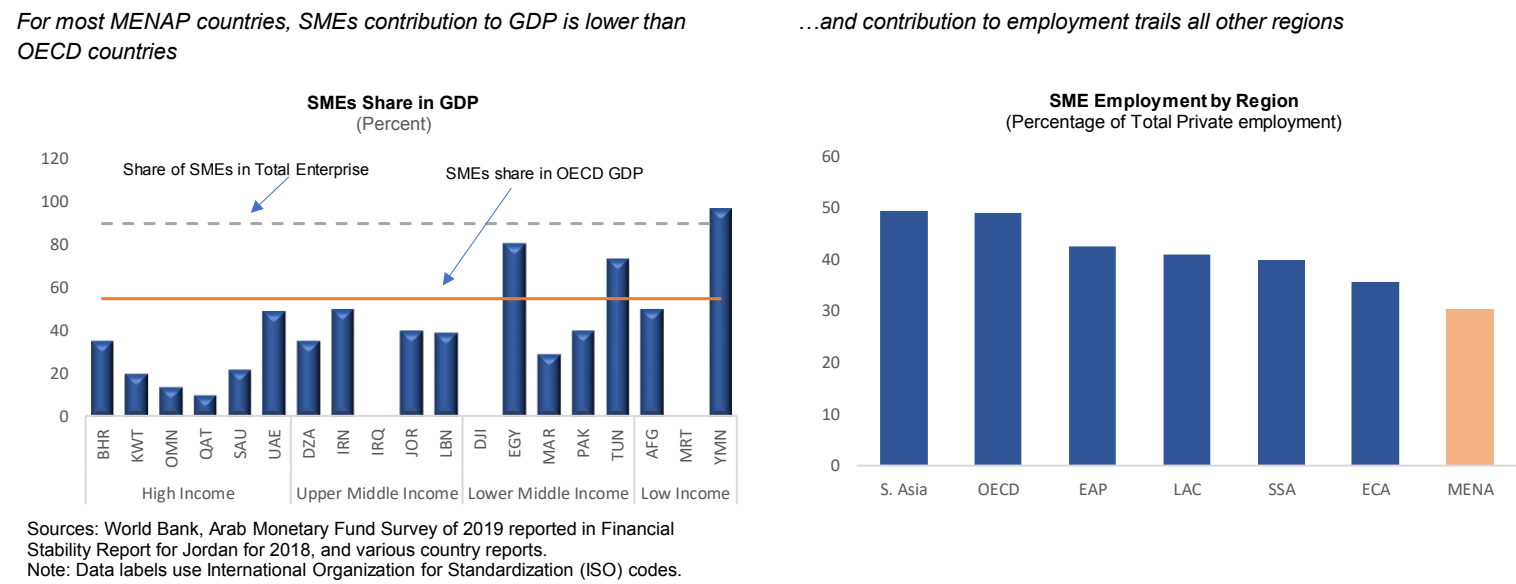

Sources: World Bank, Arab Monetary Fund Survey of 2019 reported in Financia Note: Data labels use International Organization for Standardization (ISO) codes.

MENAP SMEs funding gaps remain the highest

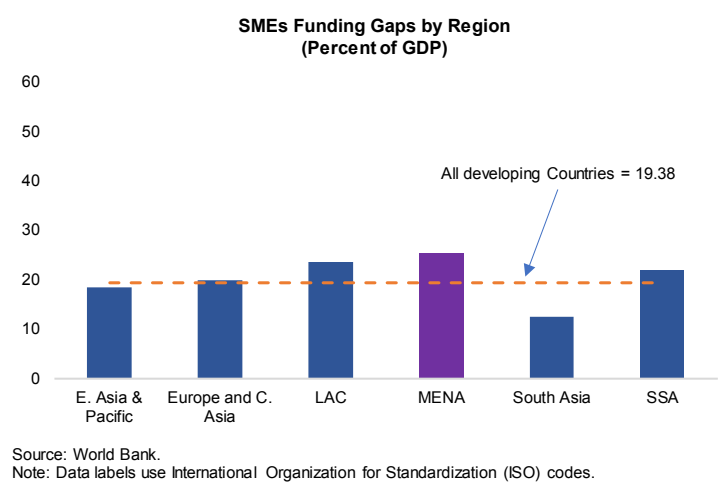

Micro-enterprise continue to dominate the MENAP SMEs sector...

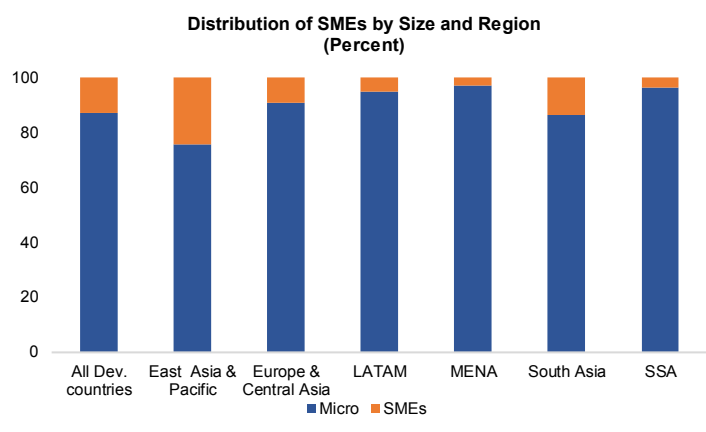

The contribution of SMEs to GDP and employment continues to be constrained by limited access to finance, talent gaps, and other structural factors. SMEs continue to experience challenges accessing financing and adequate skills to support their operations and innovate, and this has translated into a concentration of businesses in low capital intensive and value 
adding activities, such as trade and services. Microenterprises that predominate the SME sector generate limited employment opportunities (Figure 10) and are low paying, thus most educated youths prefer to take up jobs in the public sector and large corporations that offer better salaries and benefits.

\section{Figure 10. Factors Underpinning SMEs performance}

Micro-enterprise continue to dominate the MENAP SMEs sector...

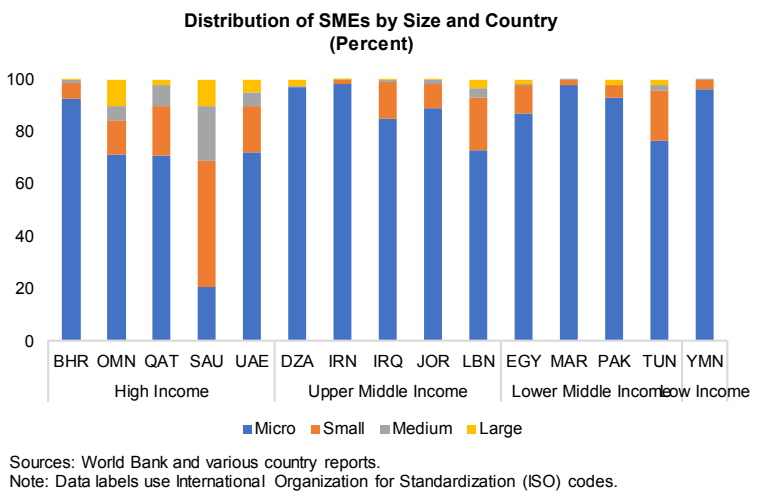

and micro-enteprises contribution to employment is low

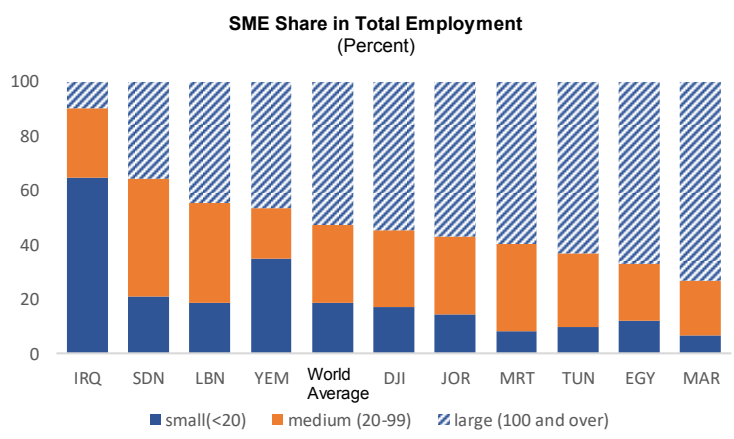

Sources: World Bank Enterprise Surveys, Latest Available Note: Data labels use International Organization for Standardization (ISO) codes.

Access to finance by SMEs remains constrained due, in part, to tensions in the SME growth strategy and partial implementation of reforms. Microenterprises that dominate the MENAP SME sector have high credit risk with low returns and are, therefore, not suitable for bank lending which is influenced by shareholders returns. ${ }^{13}$ Several credit guarantee schemes faced implementation challenges (Sharekh 2018), but they also only mitigate credit risk and not the high maintenance costs which is a more binding constraint for banks to lend to SMEs.

Implementation of infrastructure reforms has been partial, as coverage of credit registries and bureaus remain low; insolvency regimes still have low recovery rates and resolving insolvency takes several years (Figure 11). The accounting and auditing industry did not feature in the reform programs even though lack of accounts is cited by banks as an important constraint. Few countries enacted secured transaction laws or established collateral registries to enable SMEs to pledge moveable collateral.

\footnotetext{
${ }^{13}$ Many startups fail within the first 3-5 years of launch, and although those that survive and successfully scale up can give high investment returns, the high risk-reward render them unsuitable for bank financing.
} 


\section{Figure 11. Selected Factors Impeding SMEs' Access to Finance}

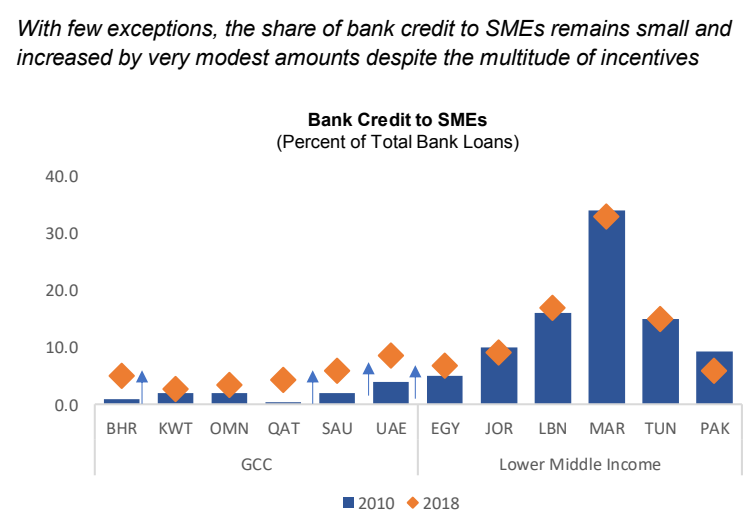

Source: World Bank and Central Bank Financial Stability Reports

The time required to resolve insolvency has reduced but not by adequate magnitudes

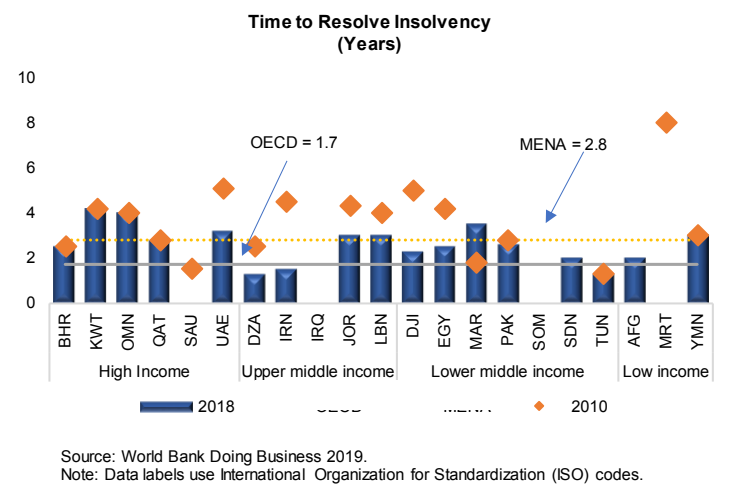

Coverage of credit registries and bureau remain low, thus information asymmetr persist that constrain banks' ability to assess SME credit risk and extend credit

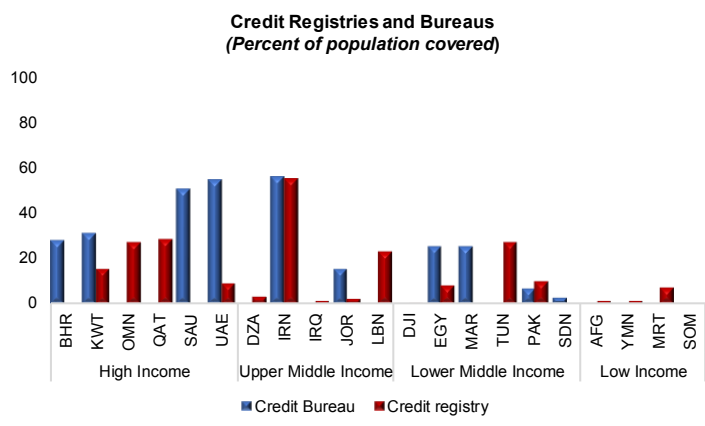

Source: World Bank Doing Business Indicators, 2011 and 2019

Recovery rates in insolvency remain low

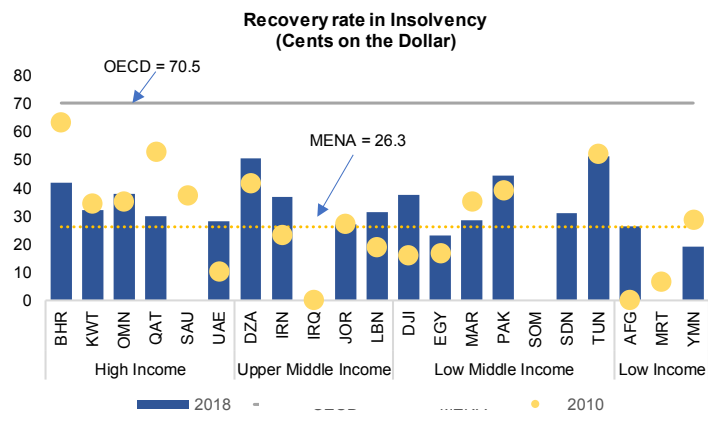

Nonbank funding sources remain scanty due to tensions in the strategy and lack of an enabling regulatory environment. Stock markets are more suited to medium-large sized companies and not the microenterprises that dominate MENAP SMEs. In some countries (GCC), SMEs have easy access to other financing such as family funds, and there is a general preference in the region to own companies and less willingness to give up equity. Private equity funds have increased but remain concentrated on early stage funding, capital for the growth stage remains scarce, and investors are geographically concentrated. Reforms have given limited attention to developing MFIs and leasing, which is more suitable for microenterprises. ${ }^{14}$ Ijara, which is a form of leasing in Islamic banks, has also been slow to develop (Figure 12).

\footnotetext{
${ }^{14}$ Leasing remains constrained by a lack of clarity on the definition of leasing, the rights and responsibilities of parties to a lease, lack of registries for leased assets, ineffective rules for repossessing assets, and tax rules that do not recognize lease as a financing mechanism.
} 


\section{Figure 12. Factors Constraining Funding from Non-Bank Financial Institutions}

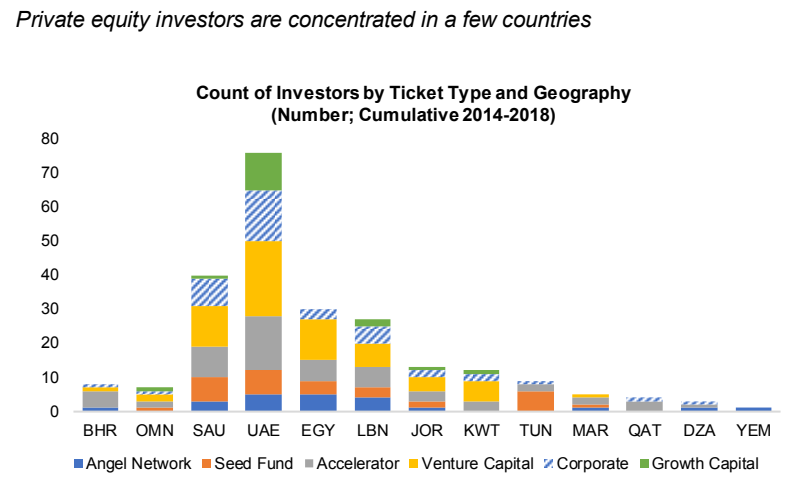

Source: The State of Digital Investments in MENA 2013-2018, Arabnet Intelligence in Partnership with Dubai SME Note: Data labels use International Organization for Standardization (ISO) codes.
.. and consist largely of early stage capital investors.

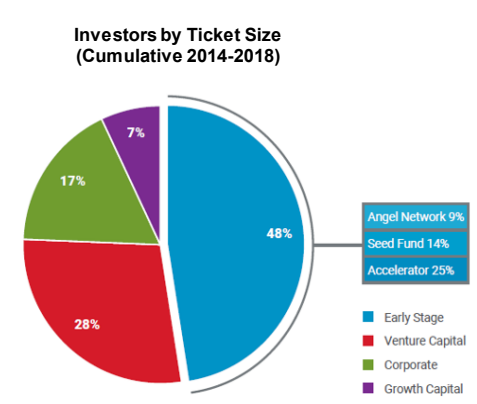

Cumulative years: 2004 to 2018 .
Base: 242
MENA MFIs penetration rates are among the lowest in the world

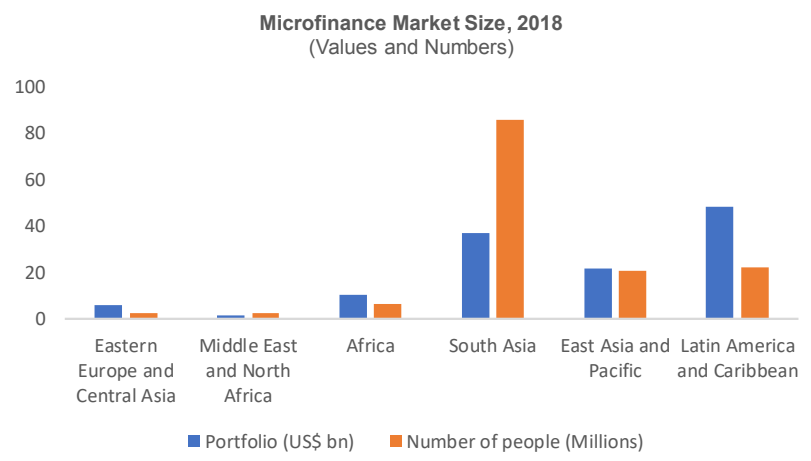

Source: MIX, Microfinance barometer 2019
... and ljara (leasing) which is more suitable for SMEs is prevalent in a few countries only.

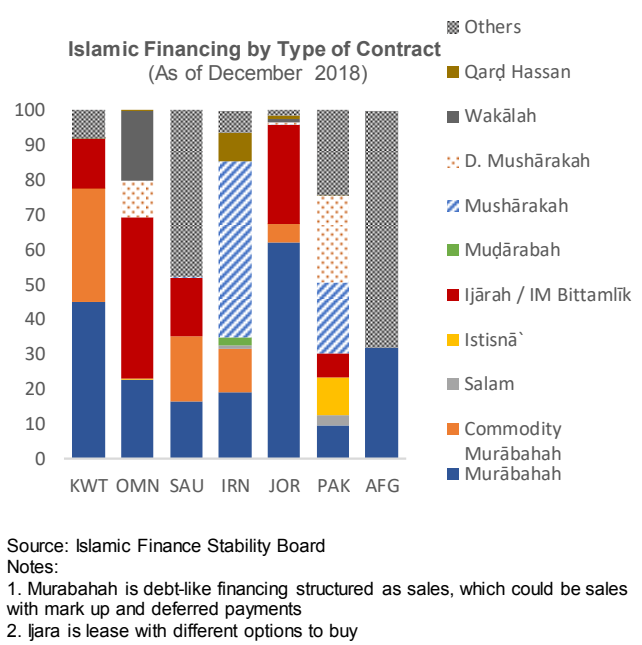

with mark up and deferred payments

2. ljara is lease with different options to buy

The business environment is still not adequately enabling as reforms have not gone far enough in key areas for business creation (Figure 13). Despite the introduction of one stop shops, the number of procedures and time it takes to establish a business remains onerous in several countries. The cost of starting a business has gone down for many countries, but the tax rate remains very high and complex in some of the non-GCC countries, and this encourages informality. The adverse impact of corruption on SMEs has begun to attract policy attention, but governance reforms take long to materialize. Many countries also perform poorly in benchmarks on enforcing contracts, dealing with construction permits, registering properties, and trading across borders. 
Figure 13. Business Environment for Starting and Operating a Business
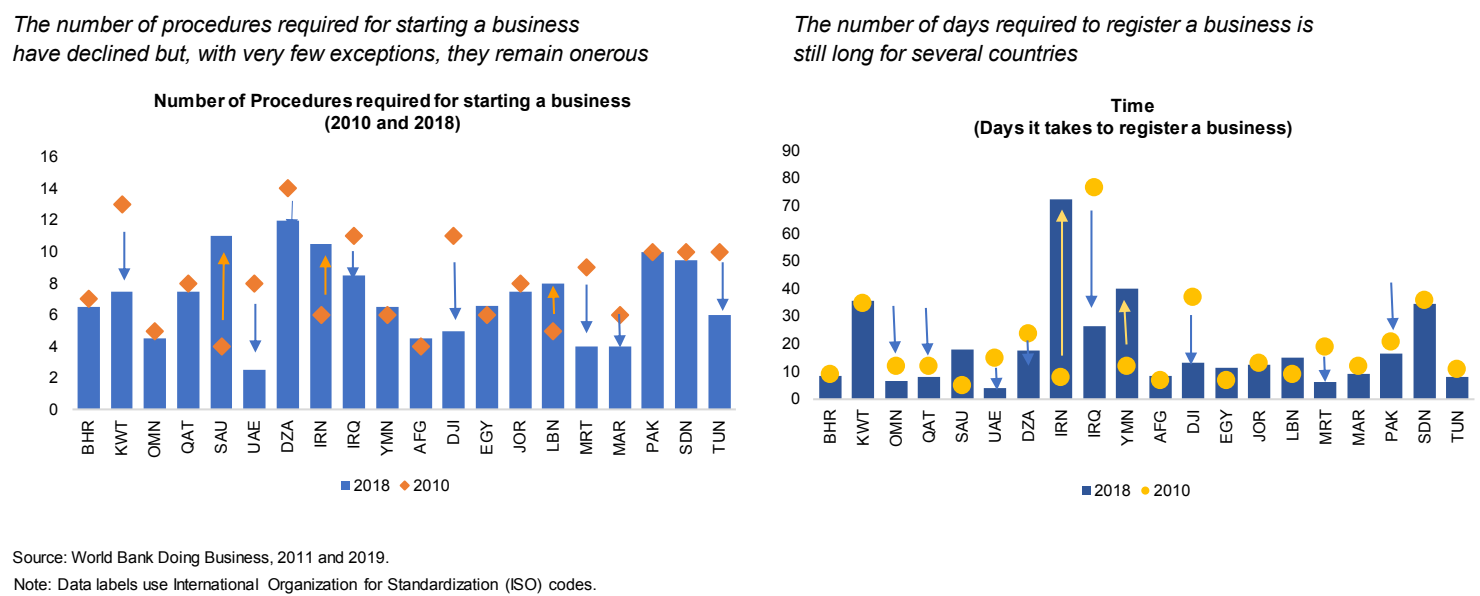

Note: Data labels use International Organization for Standardization (ISO) codes.

The institutional frameworks for supporting SMEs is fragmented in many countries, and data for policy formulation and monitoring are lacking. Many countries have multiple agencies and programs to promote SMEs, which lend themselves to duplication and coordination challenges. The policies have not been differentiated according to the scale and characteristics of the SMEs. Structural and demographic statistics on entry, exit, growth, and job creation of SMEs to support quantitative analysis that can enhance proper assessment and the decision-making process are lacking across the region. Most SMEs in MENAP countries are informal, and thus not registered and most countries do not conduct systematic enterprise surveys.

Business support services have focused more on technology startups than the broader SME sector. Countries that have developed accelerators, business incubators, technology and finance clusters, and techno parks have focused more on technology startups, and many of the facilities are concentrated in the capital cities and not rural areas. SMEs in traditional sectors, therefore, continue to face important constraints related to internal capacities and talent.

Government dominance presents a unique set of challenges. In several MENAP countries (GCC, Algeria, Iraq, Lebanon, Tunisia) governments play a dominant role as employer, consumer, producer, and financial service provider. High public sector salaries in most of the GCC make it difficult for SMEs to compete for talent and discourage educated youth from working at start-ups (WAMDA 2016). Funding of large fiscal deficits from the domestic banking systems (Egypt, Yemen, Lebanon, Algeria) constrains credit supply to SMEs.

Some macro and regulatory policies have unintended adverse effects on SMEs. Governmentenforced interest rates caps have the unintended effects of constraining banks' ability to appropriately price risks and, inadvertently discourage lending to SMEs. Pressures to comply with anti-money laundering and combating financing of terrorism (AML/CFT) regulations 
have led to de-risking and systematized reduction in bank exposures to SMEs in some countries.

Inadequate investments in infrastructure, restrictive regulatory frameworks, and idiosyncratic factors also erode the effectiveness of the incentives. In several countries (Afghanistan, Djibouti, Mauritania) an unreliable electricity supply constitutes a binding constraint to SME growth. Geo-political tensions in several countries (Iraq, Yemen) have created an unfavorable business climate for private sector development, including SMEs. Start-ups wishing to expand regionally are hindered by high regulations and visa requirements and the different regulations impose compliance burdens.

\section{Digitalization OF SMEs in MENAP-OVERVIEW, OPPORTUnities ANd Trends}

\section{A. An Overview}

The OECD (2019a) define digitalization as the use of data, digital technologies, and interconnections that results in new or changes to existing activities. The conversion of analogue data and processes into a machine-readable format — known as digitization — has made gathering, storing and managing data amenable to algorithmic management, while the proliferation of devices and sensors has increased capacity for acquiring and managing data — termed as "big data" and "Internet of Things (IoT)." In this highly connected environment, algorithms create value from data and the data improves algorithms, leading to "machine learning (ML)" and the development of Artificial Intelligence (AI). Distributed ledger technology (block chain) enables open shared and distributed public record of information that cannot be altered. Cloud technology, with its cost-efficient processing capabilities and data storage possibilities, unlocks the potential of blockchain, AI, and IoT.

The growing interaction between data, algorithms, things, and people translates into a "datadriven" or digital economy and society. This transformation makes data a resource and an asset to be traded that underpins the trade of other goods and services. The new generation of technologies - Big data, IoT, AI, ML, cloud computing, and blockchain - are also transforming how value is created, how businesses are connected, how goods and services are delivered, and the speed with which services reach end users and across borders. With digitally savvy millennials accounting for large shares of the populations, consumer expectations have changed to increasingly value goods and services, not just for their utility and cost, but also for the speed and convenience with which they are delivered. SMEs, therefore, need to digitalize to meet consumer expectations and remain competitive.

Broadband internet is a critical input in the transition to the digital economy. It is the foundation for digital services, applications, and business models and is a pre-requisite for the adoption of other digital technologies. Broadband networks encompass international, 
domestic backbone and backhaul, and local access connectivity. ${ }^{15}$ All three network components need to be in place and optimally utilized to facilitate access to affordable and reliable broadband connectivity that can support digitalization of businesses, including SMEs. Internet Exchange Points (IXPs) are also vital for improving the affordability and quality of broadband connectivity, within and between countries, by ensuring Internet traffic remains 'local' within the network of connected networks, thereby keeping costs and latency low.

SMEs' growth prospects can be significantly boosted through enhanced access to affordable broadband internet and digital technologies. Going online enables SMEs to reach new clients and markets at low cost, reduce communication costs, and conduct business during the lockdowns. Big data, cloud computing, IoT, AI, and ML improve efficiencies, reduce capital expenditures and operational costs, and speed up cross-border transactions (see Appendix 1 for more details). Through these channels, broadband internet and digital technologies help firms scale up faster, increase employment and boost output growth.

But for digital dividends to materialize, countries need robust digital ecosystems. The principal elements of the ecosystem are depicted in Figure 14. They include availability of affordable high-speed internet, a labor force that has digital skills, digital platforms to connect businesses with consumers, and digital financial services. Other important elements include digital identities (IDs), interoperable digital payment systems to facilitate transactions, digitally literate consumers, affordable devices and an entrepreneurial culture. There is also need for a reliable supply of electricity, e-commerce logistics, and digital identification and data centers for cloud computing. A robust regulatory framework is also needed that promotes innovation while mitigating risks, such as cyber risks, data protection and privacy, consumer protection, fraud, and money laundering.

\footnotetext{
${ }^{15}$ International and regional infrastructure provides connection to the rest of the world, the national backbone and backhaul then carriers traffic from international gateways to other regions of the country, and access networks or local loop provides the links between the domestic backbone to the customers, and uses either fixed or mobile broadband technologies.
} 
Figure 14. Pillars of a Digital Ecosystem for Enterprises

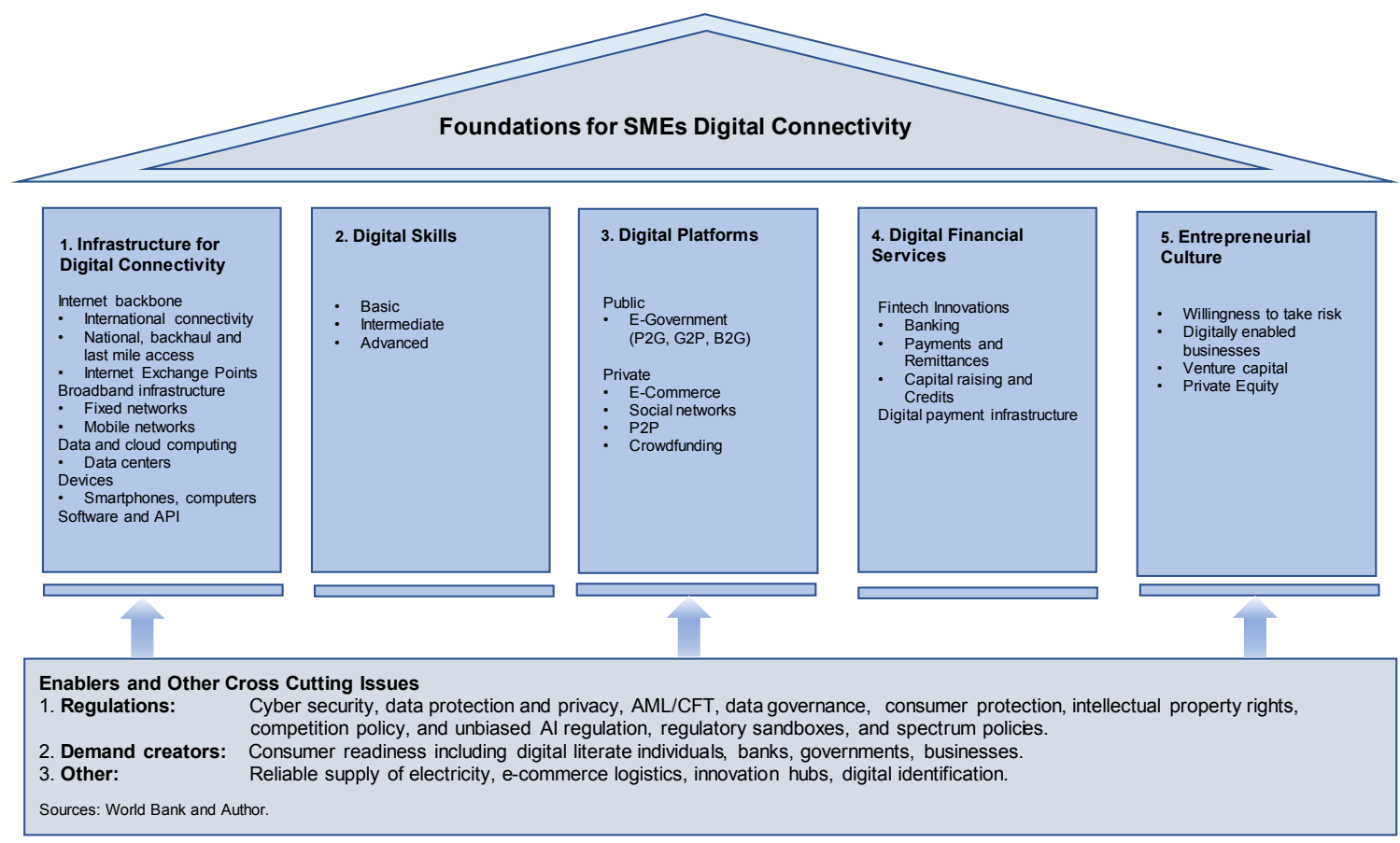

\section{B. Opportunities and Risks}

Digitalization presents immense opportunities for MENAP SMEs and has become a strategic imperative, but risks will need to be managed. Principal benefits for the MENAP region are the growth of SMEs and resilience to shocks, generation of quality employment opportunities and the associated reduction in poverty, income inequalities, gender inequalities in the labor force and inclusive growth that can ease potential for social unrest. These benefits are, however, contingent to mitigating the risks.

Digital solutions can directly boost MENAP SMEs' growth and employment creation, thereby contribute to the realization of the policy objective of inclusive growth. Efficiency and productivity gains enabled by digital technologies can help accelerate the migration of SMEs from microenterprises to larger firms that are more resilient and competitive with greater scope to create employment. Given the sectoral concentration in trade and services, broadband internet will facilitate businesses' ability to reach new clients and markets at low cost and allow for business continuity during the lockdown. IoT enables efficiencies in stock management and transportation, while Global Positioning System (GPS) Apps can help ease logistical challenges and promote e-commerce. ${ }^{16}$ Cloud-based services can help alleviate

\footnotetext{
${ }^{16}$ Many countries in MENAP don't have postal codes and this makes locating an unfamiliar residential address very challenging when delivering products ordered online. New apps with GPS functionality can now help locate a recipient using their phone numbers and ease last minute delivery challenges.
} 
financial and talent constraints by reducing ICT upfront capital expenditures, provide ICT expertise, improve digital security, and benefit from lower cost cloud-based communication services. Big data analytics can improve customer service.

Besides the job creation arising from SME growth, digitalization promises other employment advantages. Digital jobs and skills are better able to adjust to new technological demands. The jobs are also likely to come with a more flexible working culture that allows selfemployment and remote work. For the MENA region where the exclusion of women from the labor force and youth unemployment are high, digital solutions provide women and youth more opportunities to participate in the labor force. Additionally, these jobs can help countries realize national plans for digitizing their economies (PwC 2017). Though the total number of jobs created by start-ups in MENAP is still small, technology-enabled businesses have potential to generate employment opportunities through network effects. ${ }^{17}$

Digital technologies can also facilitate SMEs' access to credit and ease a key impediment to SME growth. Electronic payments create a digital trail of transactions that enables banks to lend to SMEs against cashflows where audited accounts and collateral are unavailable. Digitizing payments across supply chains can also help SMEs optimize account receivables and free up cash flows for working capital. Big data enhances banks' credit risk assessment capabilities, improves AML/CFT compliance, which can reduce wholesale de-risking that has disproportionately impacted SME lending, and enables banks to create products tailored to SMEs. Blockchain facilitates faster cross border payments and the establishment of reliable electronic registries of leased and moveable assets, thereby enabling SMEs to pledge moveable collateral. ${ }^{18}$ Digital innovations - crowdfunding and P2P platforms - help provide alternative funding sources.

A digital government could also help reduce costs and improve outcomes. E-government services can enhance the quality of interactions with businesses and citizens, such as facilitating more transparent tender processes, and reducing time for business registration and tax compliance. Internet and other digital applications (AI, ML) can facilitate electronic reporting and the development of structural and demographic statistics on SMEs to provide perspectives on entry, exit, growth, and job creation. More granular data on SMEs facilitates evidence-based policies and better monitoring and analysis of regulatory policy impact, which improves the effectiveness of SME policies. Moreover, the significant size of the public sector in most countries and the pervasiveness of making payments to, or receiving payments from, governments mean that when authorities introduce digital payment options,

\footnotetext{
${ }^{17}$ For example, Alibaba has 30,000 employees, but provides a platform for more than 10 million ancillary jobs. Uber has a few hundred coders, but it supports the livelihoods of around 1 million on-demand drivers (World Bank 2016b).

${ }^{18}$ For instance, Georgia has successfully created an electronic land and property registry using blockchain.
} 
they can influence the behavior of a mass of individuals, incentivizing them to switch to digital payments.

Digital innovations in payments can facilitate efficiencies in domestic and cross-border trade and reduce costs which are currently high in the MENA region. Digital payments infrastructures enable real time payments that increase operational efficiencies and blockchain has emerged as a key technology to facilitate international remittances and other cross-border transactions. Payment instruments (credit and debit cards) also alleviate payment delays and reduce cash management costs.

Digital dividends can, however, be neutralized if risks are not well managed (IMF 2019). The "data-driven" economy and society has made data an asset to be traded and a resource that underpins trade of goods and services. How to fully exploit the potential of data to stimulate innovation and productivity while protecting privacy, intellectual property rights, and ensuring security is a new challenge. Increasing connectivity and dependence on technology also increases IT risks, and broadens the threat landscape for cybercrime, digital fraud, money laundering, biased AI decisions, as well as fake news, such as deep fake. ${ }^{19}$ SMEs have not been the target of cyber criminals, but they lack in-house IT expertise to monitor and secure their networks and devices. Further, without appropriate retooling programs, automation can also displace labor and increase unemployment.

\section{Trends in SMEs Digital Transformation}

Businesses in MENAP have generally been slow to adopt the internet to boost productivity despite many governments' initiatives to promote digitalization (Figure 15). The digitalization process has not followed the path typically seen in other markets where consumers moved online and businesses immediately followed, enabling a gradual development of the digital ecosystem. In MENAP, mass internet adoption, especially in the GCC, took off around the mid-2000s, but businesses only began to digitalize after 2010 (Fabre et al). The internet continues to be used mostly for entertainment and to communicate and much less to make transactions or to innovate, thus businesses trail governments and consumers in internet usage (McKinsey 2016).

\footnotetext{
${ }^{19}$ In MENAP, cyber-attacks particularly targeting the GCC have been increasing (Symantec 2019). Policy makers are giving these risks increasing attention, but many countries have not developed solid digital strategies.
} 
Figure 15. Trends in Internet Adoption and Business Digitalization
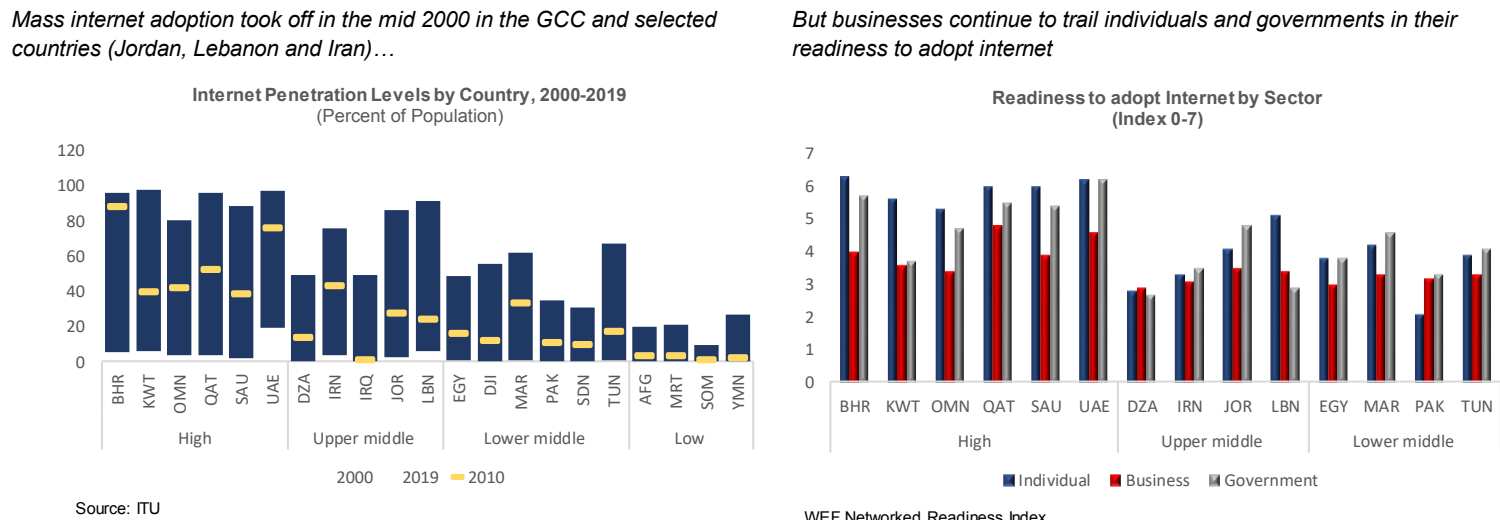

WEF Networked Readiness Index

SMEs in MENAP are increasing their digital presence, but their overall footprint remains small (Figure 16). Despite the increase in internet usage among the population, only 15-25 percent of SMEs in MENAP had online web presence at the end of 2012 (Deloitte 2014), and recent surveys indicate that these shares have only marginally changed (WTO 2019). Use of social media platforms such as Instagram and Pinterest by SMEs has increased, but the technological absorption at the firm level shows that firms in the middle to lower income countries are lagging in embracing technologies in their business operations (WEF 2019). Data centers have cropped up that are facilitating the adoption of cloud computing but deployment of cloud services by SMEs remains low. ${ }^{20}$

\section{Figure 16. Web Presence and Cloud Adoption by SMEs}

Despite internet penetrations that are comparable to advanced economies online web presence of SMEs in MENA is Iow

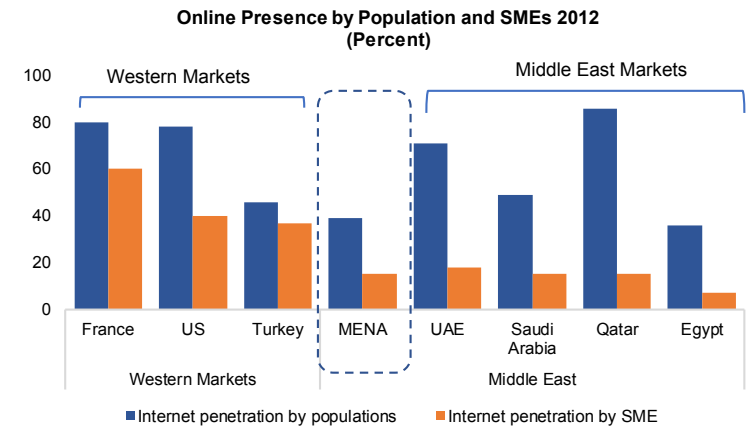

Source: Google Survey 2013, Deloitte 2018
SMEs in MENA trail most other regions in leveraging cloud services in their operations

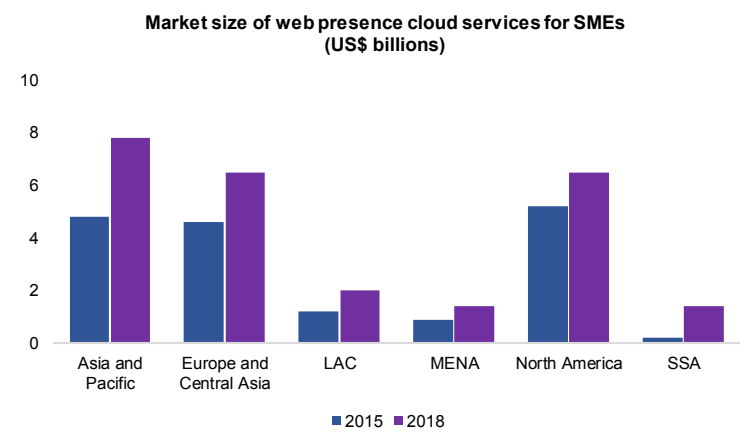

Source: Statistica 2019.

\footnotetext{
${ }^{20}$ Data centers and cloud services are provided by Microsoft, Amazon Web Services (AWS), Oracle, Alibaba, and SAP.
} 
Interest in e-commerce is growing but the share of SMEs that have embraced online trading as a consumer sales channel remains small. Data on e-commerce transactions by SMEs are scanty, but e-commerce remains generally small. E-commerce transactions for the MENA region accounts for less than 2 percent of total sales and less than 1 percent of the global ecommerce market (Fabre et al 2019). The UAE, Saudi Arabia, and Egypt account for 80 percent of the MENA e-commerce market followed distantly by other GCC countries (Bahrain, Kuwait, Oman, and Qatar) (Figure 17). Governments in several countries (GCC, Egypt, Pakistan, Jordan, Tunisia, Lebanon) have begun to formulate policies to promote ecommerce, big retail companies are increasing online sales, and several e-commerce platforms have emerged, but SMEs are still largely absent from virtual marketplaces (US Export. Gov). ${ }^{21}$

\section{Figure 17. E-Commerce Trends}

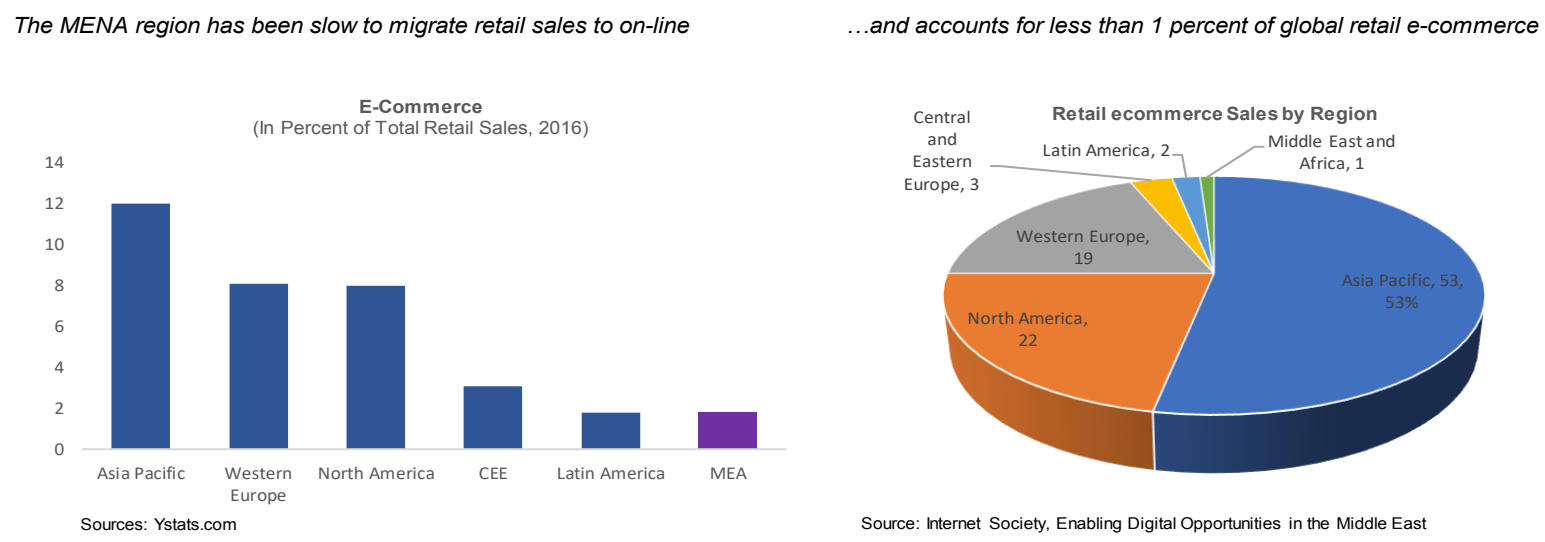

E-commerce remains underdeveloped across the region...

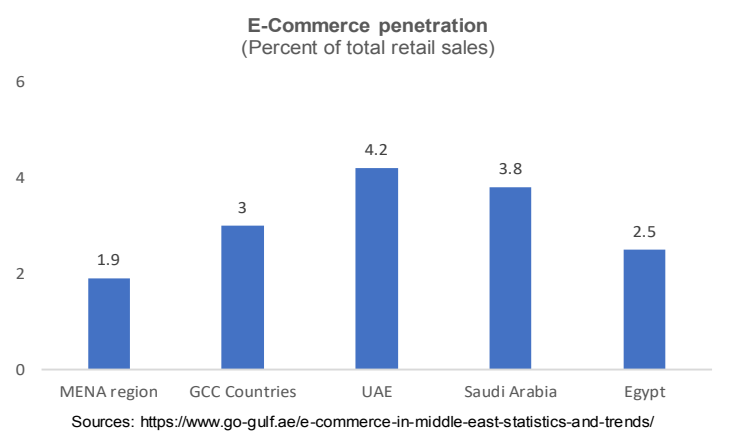

...but it is gaining momentum in some of the countries, including UAE Saudi Arabia and Egypt

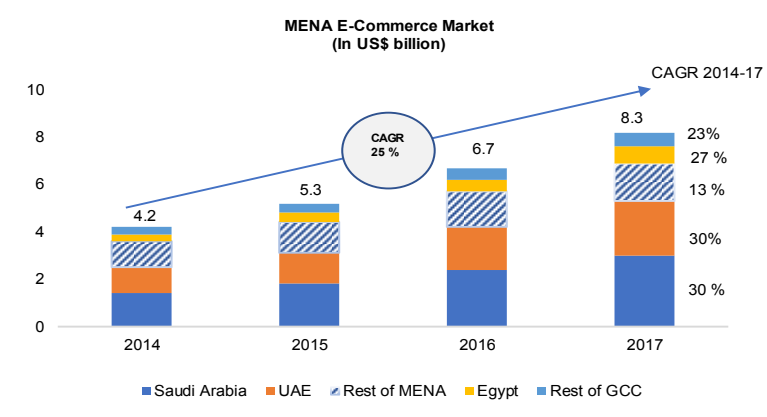

Source: Google and Bain, White Paper 2018

\footnotetext{
${ }^{21}$ In Bahrain local merchants are not utilizing online-platforms, so customers purchase goods from other markets. In Kuwait, most e-transactions are related to banking or brokerage services. Overall, the products mostly traded in online sales are consumer electronics, computers, fashion accessories, women's apparel, cosmetics perfumers, etc.
} 
Technology startups and technology-enabled businesses are increasing but activities remain concentrated in a few countries (Figure 18). Boosted by government and other initiatives, investment in technology startups grew at an annual compound growth rate of 36.6 percent. UAE accounts for 31 percent of all deals and 70 percent of funding in the region. Other countries with significant digital start-up ecosystems include Saudi Arabia, Egypt, and Lebanon followed distantly by Iran, Jordan, Kuwait, Tunisia, and Bahrain. E-commerce, fintech, technology, and transport logistics account for half the investments (Magnit 2019).

\section{Figure 18. The Digital Technology Start-up Ecosystem}

The technology start-ups ecosystem is still geographically concentrated

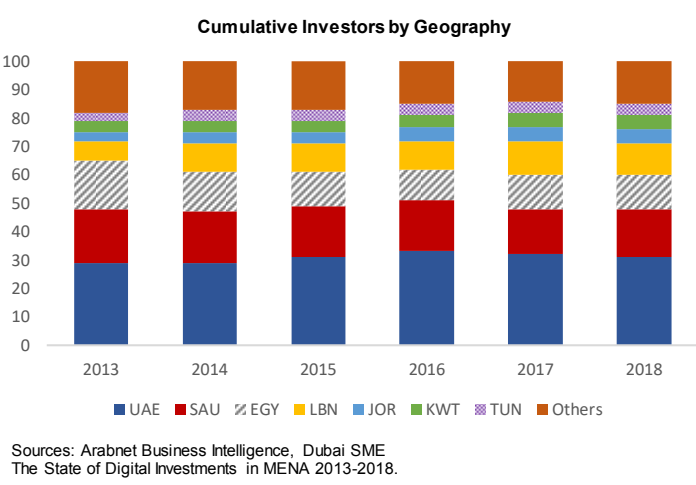

.... and most start-ups have invested in e-commerce, fintech, transport and logistics.

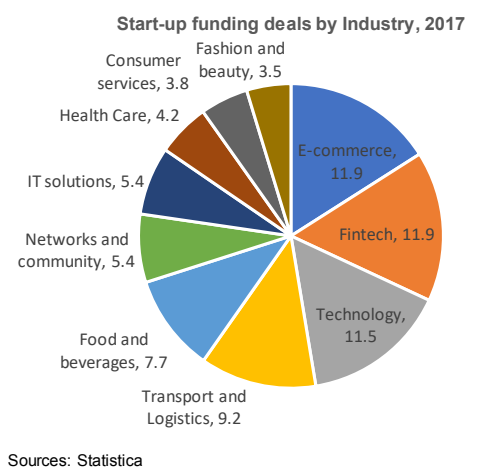

\section{The Digital Landscape and Constraints to SMEs' Digitalization}

SMEs in MENAP are at different stages of digital transformation but, generally, the preconditions for effective use of new technologies are missing in many countries. The SMEs face significant constraints on the supply side but demand factors also play an important role in slowing the digitalization process.

\section{Supply Side Constraints}

The preconditions for the development of an information and digital economy are lacking in many countries, particularly in the non-GCC MENA countries. Access to international connectivity is good but barriers to entry and competition have constrained capacity utilization. These barriers are resulting in underinvestment in national backbone infrastructures and inefficiencies across the internet value chain that manifest in low broadband penetration rates, unaffordable and poor quality internet services. Progress has also been slow in developing digital financial infrastructures, e-commerce logistics, enabling regulations, digital skills gaps and entrepreneurial culture is just emerging.

All countries have easy access to international fiber optic networks. The region is strategically positioned with respect to international connectivity as most of the submarine fiber optic cable infrastructure linking Europe and China crosses the Mediterranean Sea, the 
Sinai Peninsula, descends through the Red Sea and through the Yemen-Djibouti strait to reach the Arabian Peninsula (Figure 19). This infrastructure is complemented by terrestrial cables built across the Middle East to provide alternative connectivity between Asia and Europe (World Bank 2014; 2018). Most data traffic is, therefore, transferred internationally through submarine cables, with terrestrial fiber, microwave, and satellite transmission accounting for a smaller amount.

\section{Figure 19. Access to Global Internet Infrastructure}

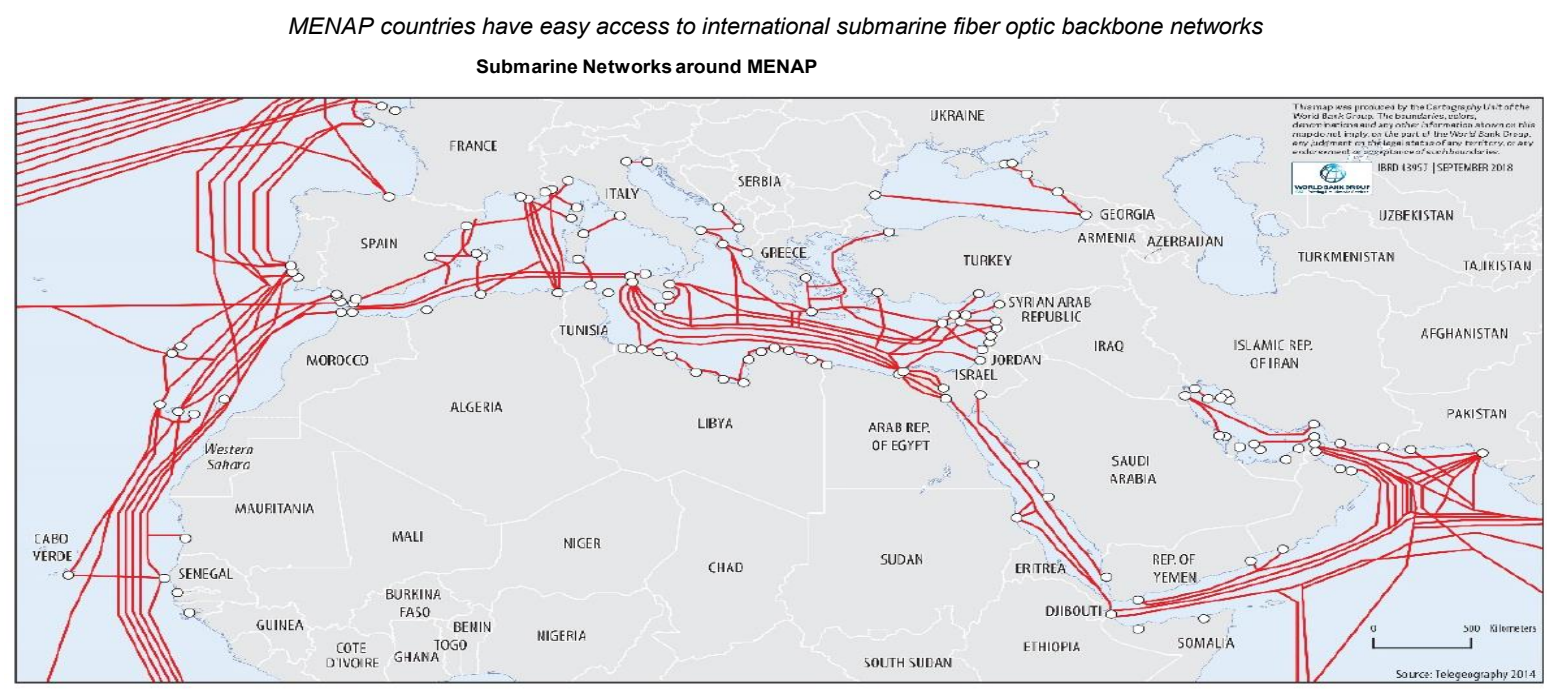

Source: World Bank, MENA Economic Monitor, October 2018.

There are also complementary landbased networks that cross the Mashreq and Gulf and provide alternative high speed routes

Terrestrial Networks in the Mashreq and Gulf

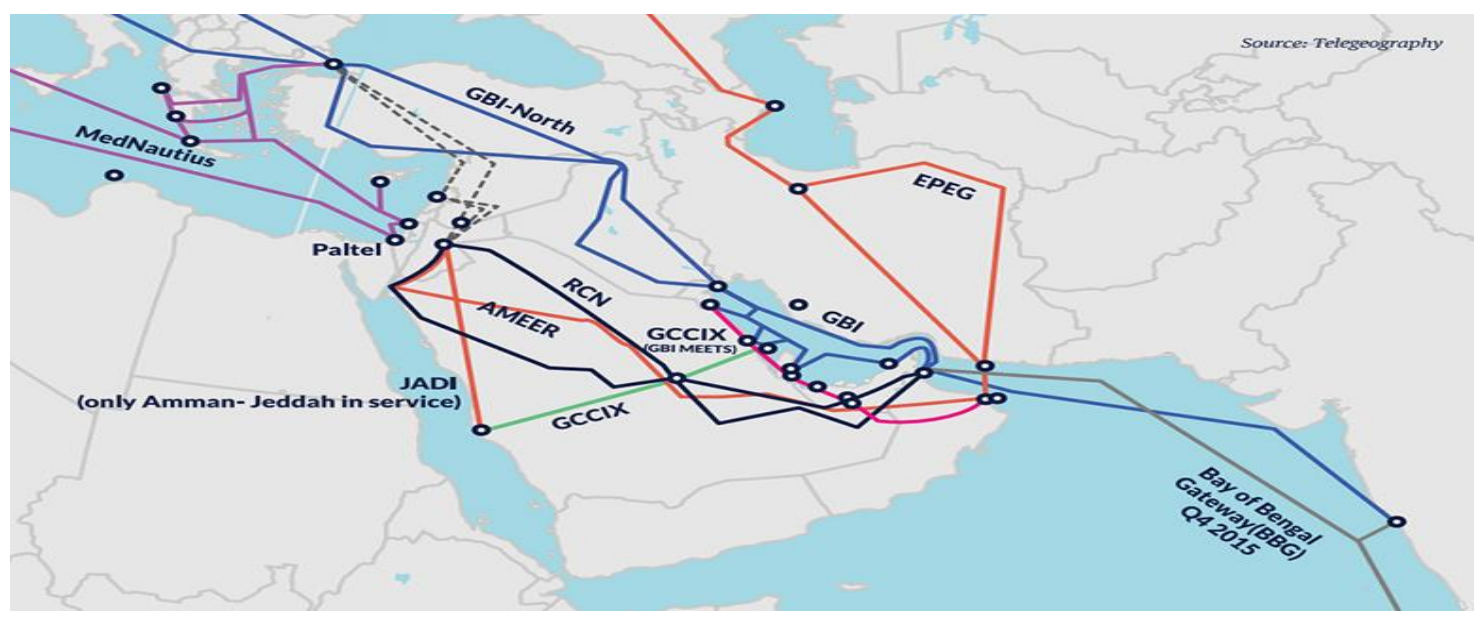

Source: World Bank, MENA Economic Monitor, 2018

Source: World Bank, MENA Economic Monitor, 2018
Notes: AMEER = Alternative Middle East Europe route; EPEG = Europe Asia Express Gateway; RCN = Regional Cable Network;

Effective use of international connectivity infrastructure is, however, constrained by lack of competition and open access regulations. Several MENAP countries restrict access to international gateways and international fixed long-distance lines in the form of monopolies 
and other restrictions to competition (Figure 20). Entry barriers constrain investment and result in capacity underutilization of international bandwidth and higher international charges, which spill over to downstream domestic markets.

\section{Figure 20. Entry barriers to the Telecom Market}
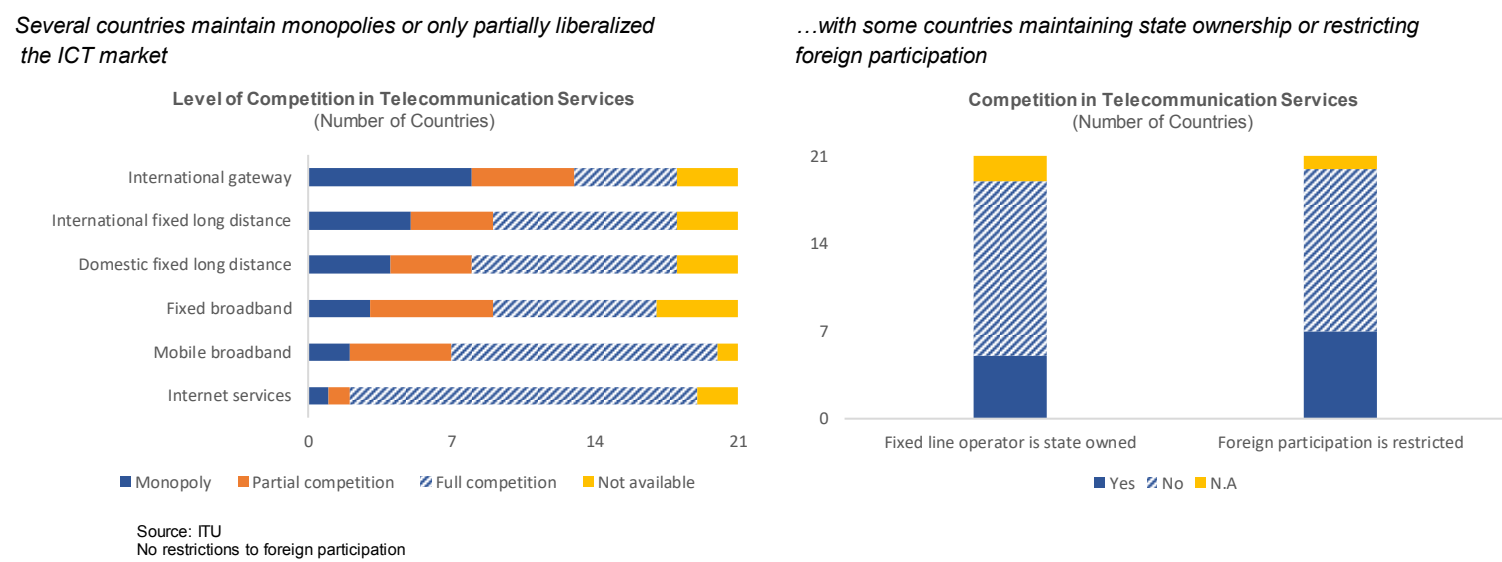

The lack of competition limits investments and innovation resulting ... in low bandwidth..

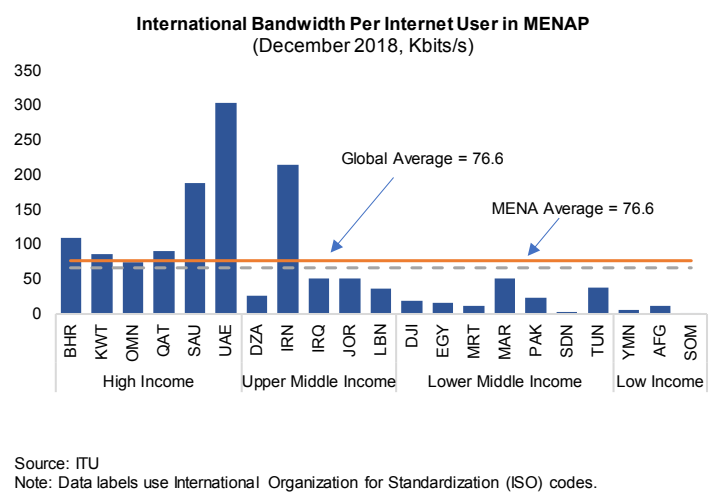

..and higher international rates measured by the Skype out rates

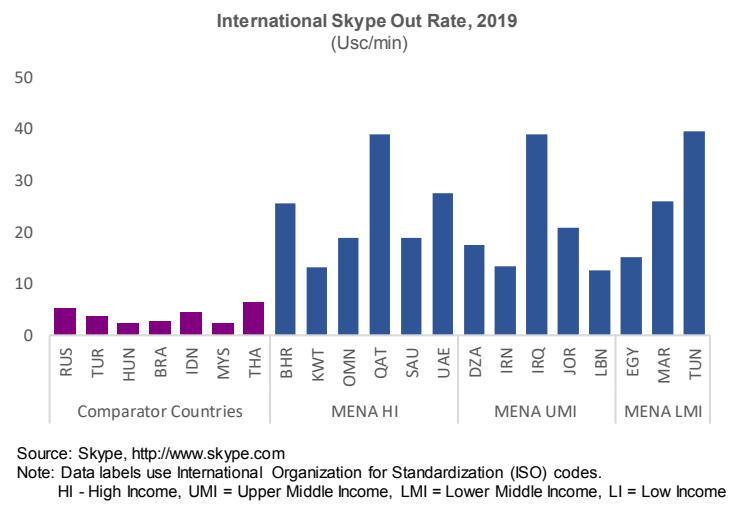

The domestic telecom market has been increasingly liberalized, but some restrictions remain that constrain investments and increase inefficiencies. For instance, a few countries (Djibouti) maintain monopolies across the whole value chain. About a third of the countries still restrict competition in their mobile and fixed broadband markets through monopolies, state ownership, or limits on foreign ownership and control (Figure 20). Restrictions on peering and network development coupled with limited market contestability have also constrained the development of Internet Exchange Points (IXPs), resulting in domestic networks having to send local traffic to Europe to exchange data before backhauling it to the Middle East. Internet services, therefore, exhibit lower latency, high costs, constrained bandwidth, and low speed, which limits adoption of cloud services that require high speed internet. 
Entry barriers and high capital investment requirements have slowed the deployment of advanced network technologies as well as the deployment of digital technologies. In the fixed broadband markets, Digital Subscriber Lines (DSL) is still the leading fixed broadband access technology, and very few countries (UAE, Qatar) have deployed fiber optic-based access technologies. Greater progress has been made in the mobile broadband market, but the agenda for further action remains large. A few countries (Bahrain, Saudi Arabia) have launched 5G, several countries (GCC, Algeria, Jordan and Lebanon) have rolled out the higher speed fourth generation of mobile telecommunication technology (4G) but most lowincome countries still rely on $3 \mathrm{G}$ technologies that are slower (Figure 21). In countries with monopolies across the broadband value chain (Djibouti) or those with geopolitical tensions (Iraq, Afghanistan, Yemen), access is limited, network quality is poor and internet costs are higher. The slow internet constrains adoption of cloud services, AI, and IoT.

\section{Figure 21. ICT Infrastructure}

In the fixed broadband market, where entry barriers are prevalent, few countries (UAE and Qatar) deploy fiber optic technologies

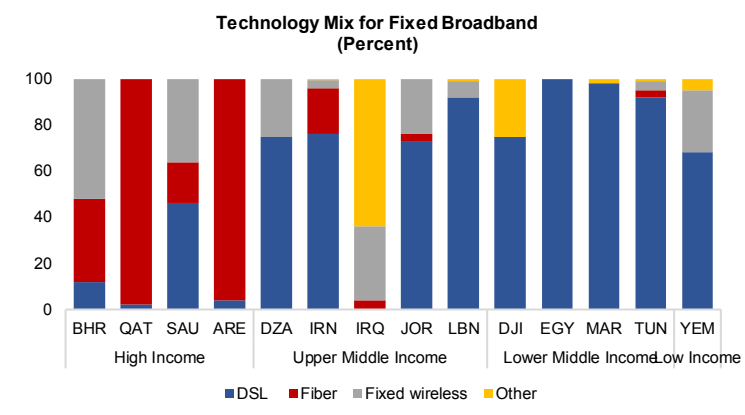

Source: Telegeography, World Bank 2018

Note: Data

The MENA region has the lowest $4 G$ coverage after SSA and CIS

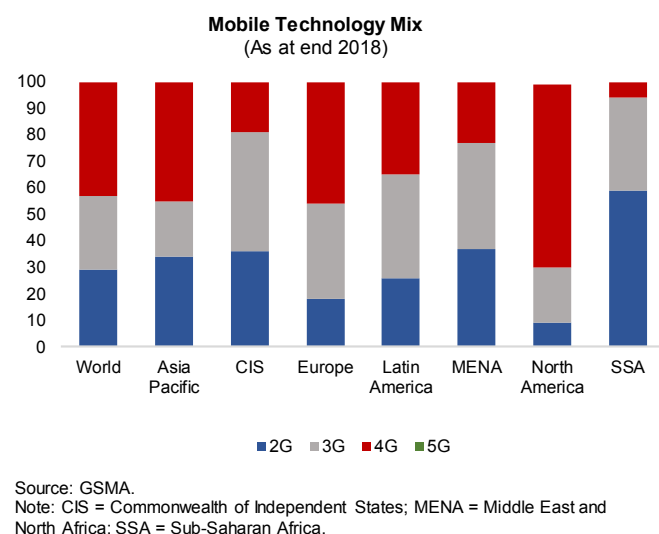

North Africa; SSA = Sub-Saharan Africa.
In the more competitive mobile markets, several countries have migrated to $4 G$ technologies although progress is uneven

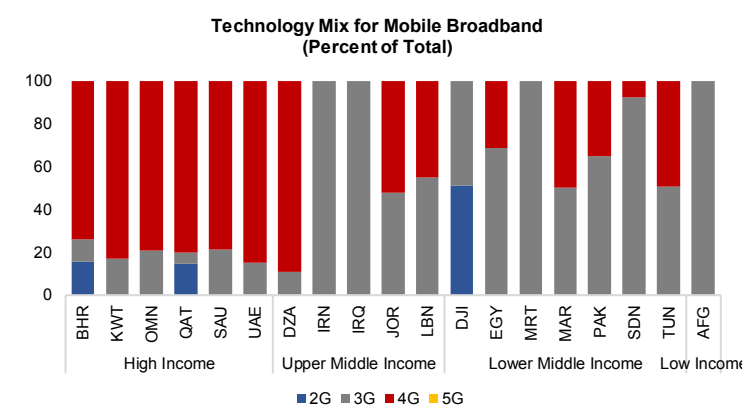

Source: Fitch Solutions, Telecommunication Country Reports. Note: Data labels use International Organization for Standardization (ISO) codes . and is trailing most other regions in developing cloud data centers

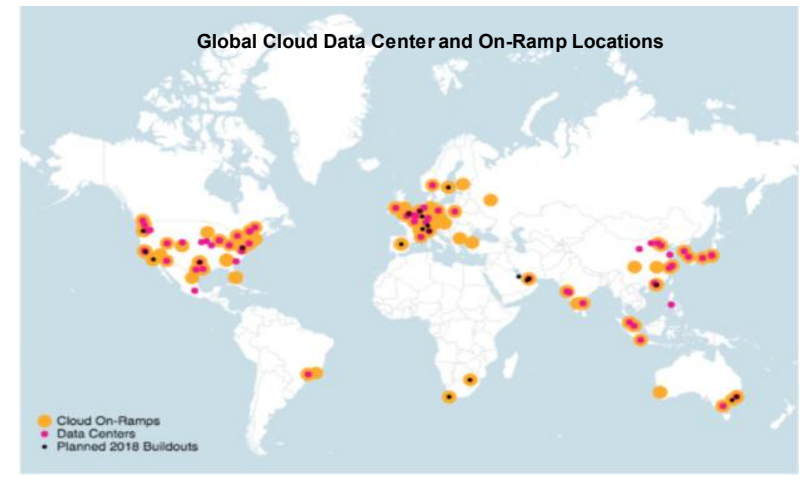

Source: Telegeography.

Access to broadband internet is limited in the lower income countries and potentially hampers the capacity of SMEs to embrace e-commerce. Fixed broadband subscriptions are the second lowest in the world after Sub-Saharan Africa (SSA) and, with few exceptions (UAE, Lebanon), all countries trail global averages. Mobile broadband has become the 
predominant platform for internet access, but subscriptions trail all other regions after SSA (Figure 22). Within MENAP, subscriptions are higher in the GCC and Jordan, while other countries are below the global average. Deploying infrastructure for rural coverage remains an economic challenge for many countries, thus a rural-urban digital divide has emerged.

\section{Figure 22. Access to Broadband Internet} Access to mobile broadband, though increasing rapidly, is still among
the lowest after SSA

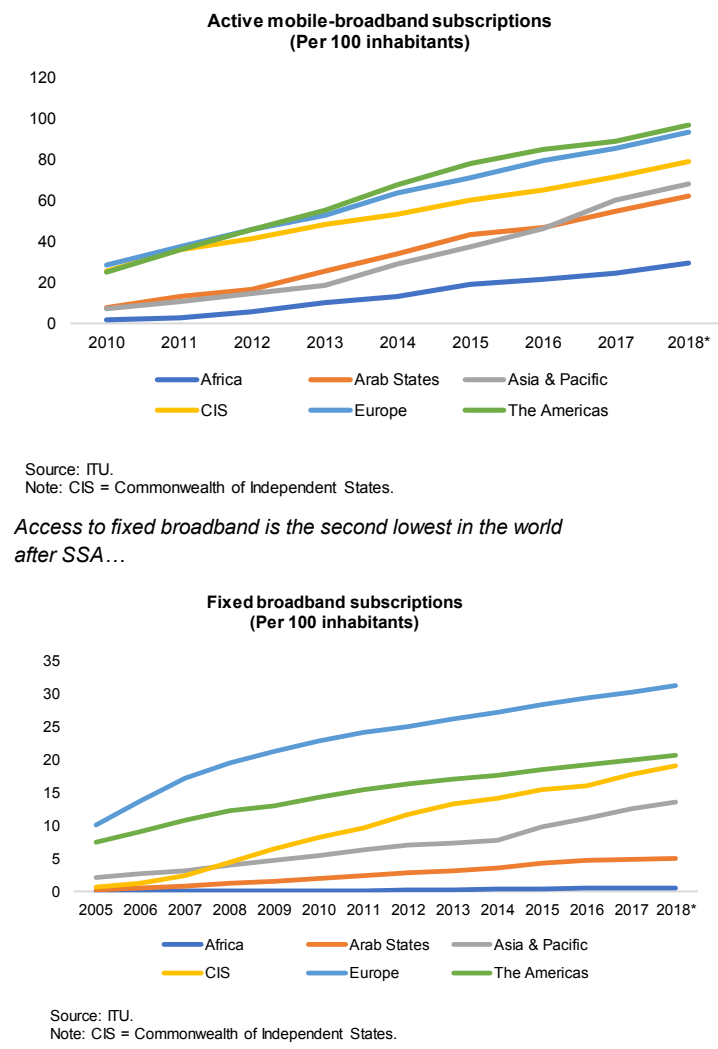

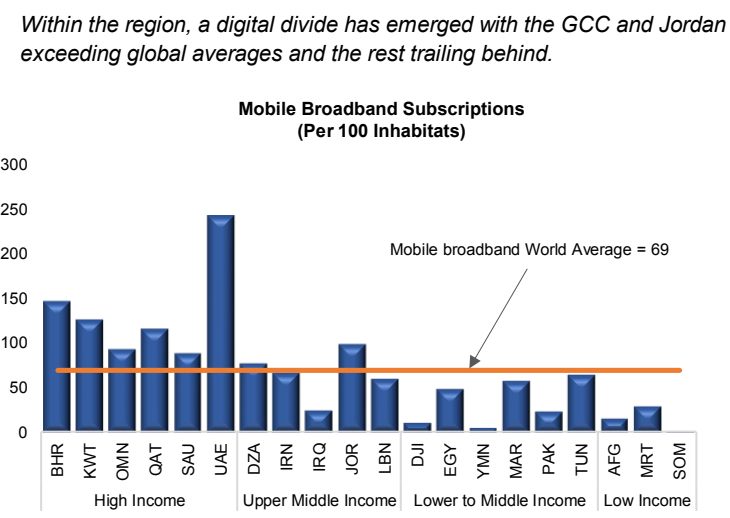

and very few countries (UAE, Lebanon) have subscriptions above world averages

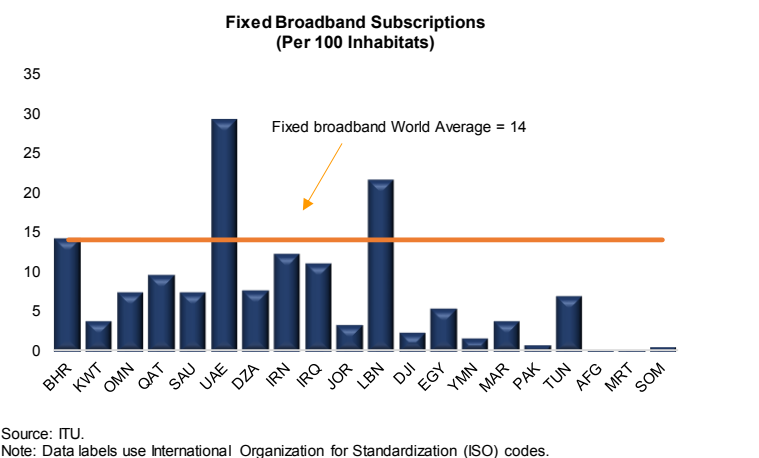

Network quality and reliability continues to improve but remains a challenge, especially in the lower income countries and this adversely impacts usage and adoption of digital solutions. Internet-connection-speeds in MENA for fixed broadband are below global averages for all countries, and the subscriptions are mostly at speeds below $10 \mathrm{Mbit} / \mathrm{s},{ }^{22}$ reflecting the slow transition to fiber optics. For mobile broadband, the GCC, Iran, and Jordan are among the few countries where the speeds are above global averages (Figure 23), reflecting advancements in rolling out $4 \mathrm{G}$ and allocation of spectrum especially above $1 \mathrm{GHz}$. For some countries general restrictions designed to limit the influence of social media negatively impact network reliability. Low download speeds constrain e-commerce which requires high bandwidth to download images and videos. The low speeds coupled with

\footnotetext{
${ }^{22}$ While there are no defined thresholds for what constitutes reasonable high-quality services, regulators consider download speeds above $10 \mathrm{Mbps}$ as decent broadband speed and $30 \mathrm{Mbps}$ is considered superfast (GSMA 2019).
} 
regulatory constraints and insufficient local hyper scale data center further inhibit the growth of bandwidth reliant technologies, such as cloud computing, IoT and AI.

Figure 23. Internet Speed

Average internet speeds for fixed broadband trail global averages...

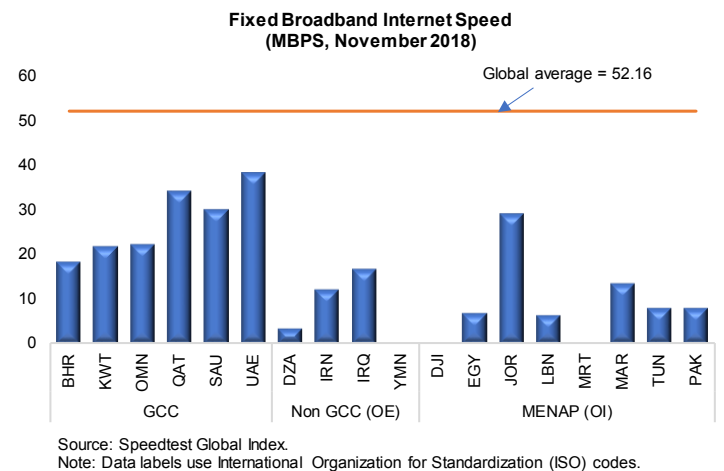

Most fixed broadband subscriptions are at speeds below $10 \mathrm{Mbit/s}$ which are lower than other regions outside SSA

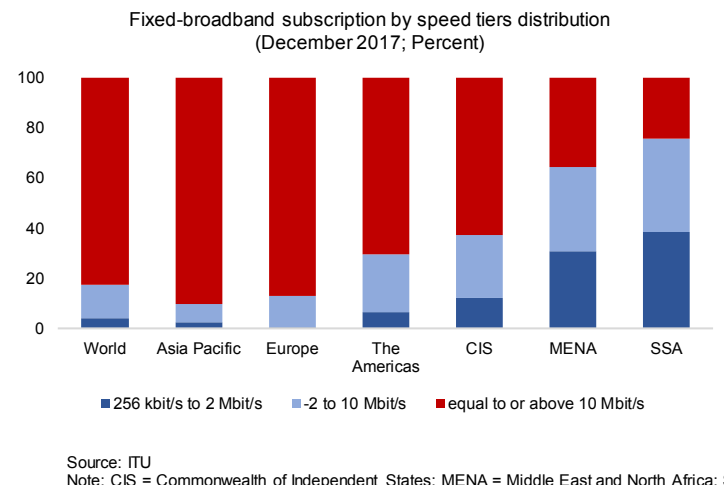

... similarly mobile broadband speeds for most MENAP countries are below global averages except for the GCC, Iran and Lebanon.

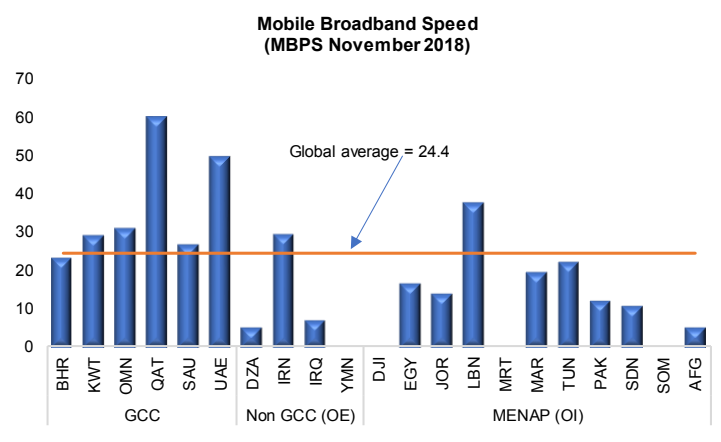

Across the region, only a few countries (Bahrain, Qatar, UAE and Jordan) provic internet at speeds above $10 \mathrm{Mbit} / \mathrm{s}$

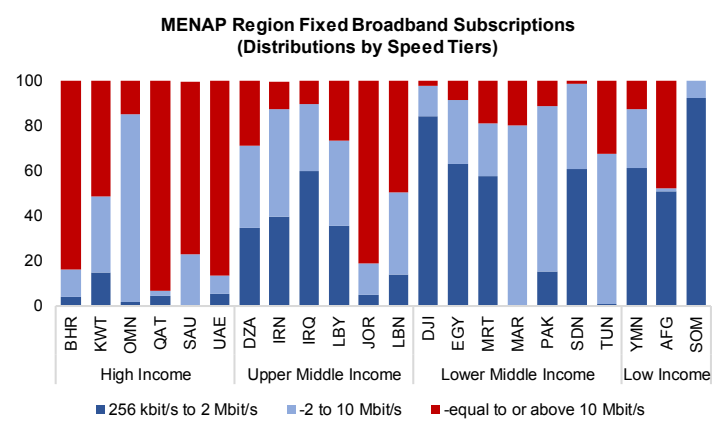

The high cost of internet also hampers the digital transformation of SMEs in MENAP. The average cost of broadband packages has been declining but remains unaffordable in several low-income countries (Figure 24). Constrained access to the international gateway and the absence of IXPs in many countries also contribute to higher international internet costs. In addition, limited competition in some countries (UAE) and underdeveloped technological infrastructure (Mauritania) also push up prices and limit capacity to provide businesses with affordable bandwidth. With regional bandwidth costs several times higher than many other countries, businesses could face comparatively higher challenges developing cloud-centric business models. 
Figure 24. Broadband Prices

Though fixed broad band prices are mostly lower than the global average

the cost of mobile broadband remains higher than global averages in several countries
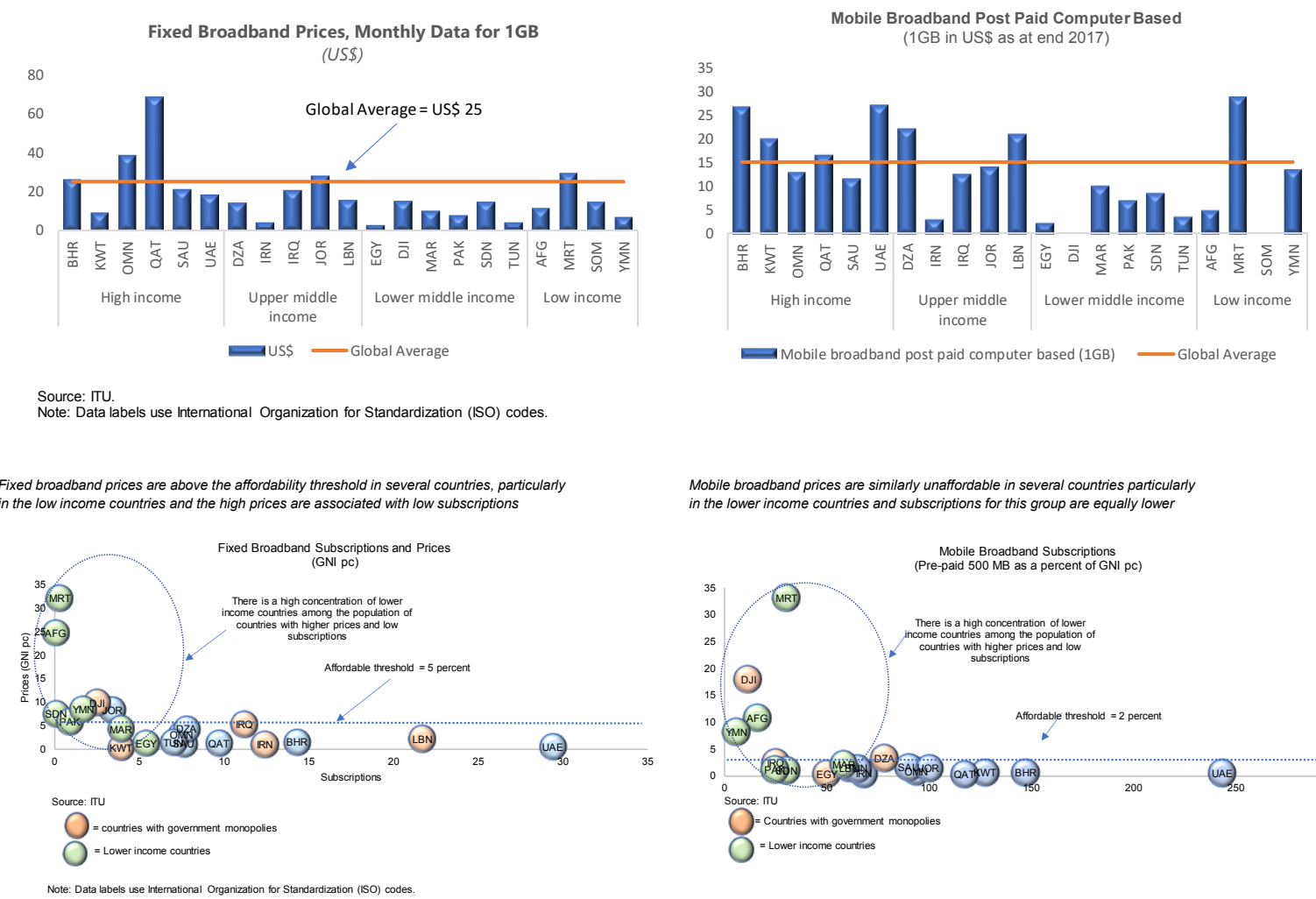

Mobile broadband prices are similarly unaffordable in several countries particularly in the lower income countries and subscriptions for this group are equally lower

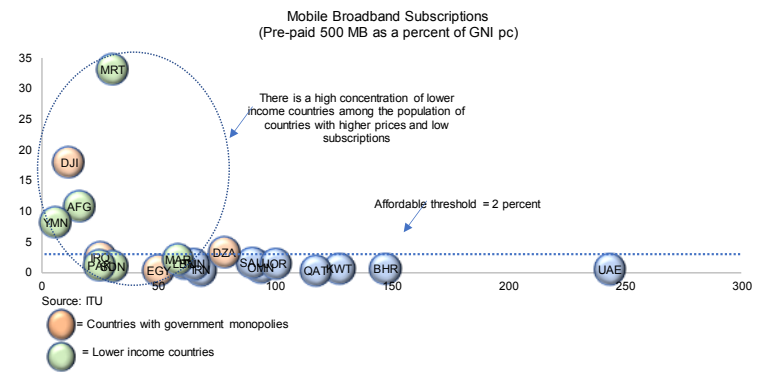

The large and growing digital skill gaps constitute another major challenge for SMEs' ability to compete for digital skills needed to adopt digital solutions. The MENAP region rates the second lowest after SSA in basic, standard, and advanced digital skills (Figure 25). ${ }^{23}$ The digital skill gaps are reported to be more acute in the areas of cloud, AI, machine learning, mobile technologies, blockchain, data analytics and advanced security (Galviz 2020). The skill gaps also cut across the region, but higher income countries, such as the GCC, have the resources to invest in education and are able to attract foreign expatriates (EY 2015). Some countries (Lebanon, Egypt) have high levels of digital expertise but suffer brain drain to other regions, including to the GCC. Low income and conflict countries face more fundamental challenges in developing their human capital through education (WEF 2016). A misalignment between educational curriculum and labor market demands together with the rapid pace of technology contributes to the gaps (EY 2015; Bricker 2019). Public sector

\footnotetext{
23 The deficiencies are reportedly more acute in the areas of cloud, AI, machine learning, mobile technologies, blockchain, data analytics and advanced security (Galviz 2020).
} 
digital transformation projects in some countries (GCC, Egypt, Jordan, Lebanon, Tunisia, Pakistan) will increase demand for IT skills relative to supply (EY 2015).

Figure 25. ICT Digital Skills
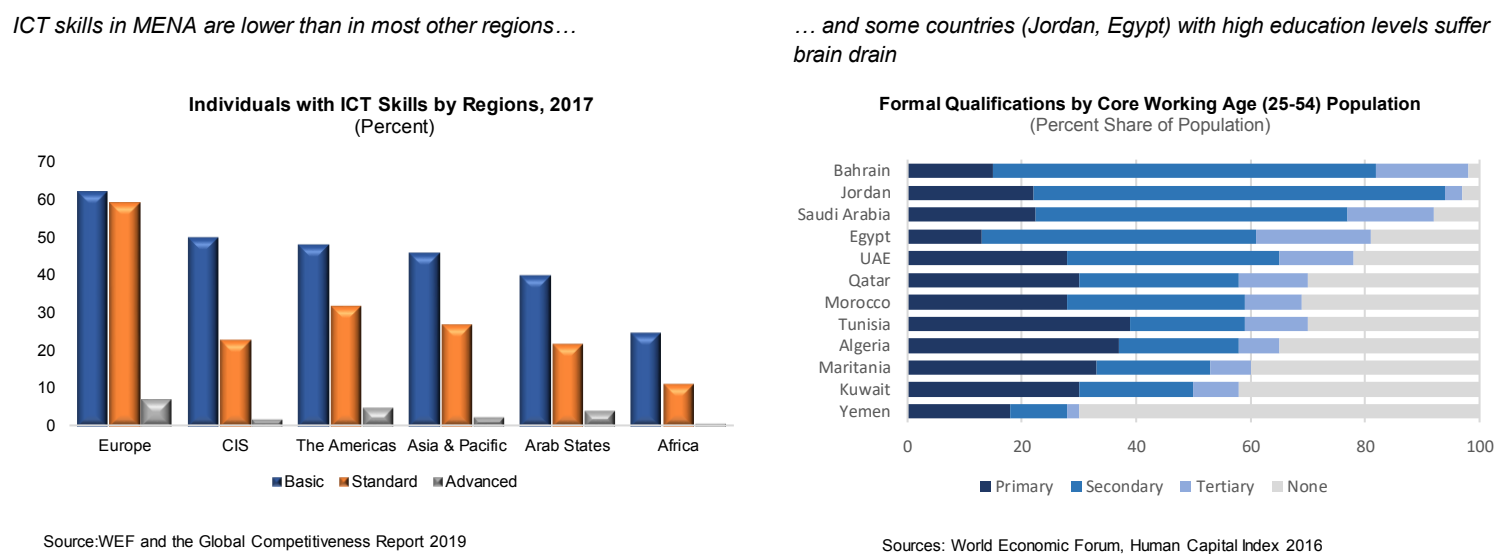

Digital financial services (DFS), though gaining momentum, do not yet provide a strong foundation for SME digital transformation across the region. The infrastructure critical for SMEs to accept electronic payments — such as Point of Sale (POS) terminals — have limited penetration, in part reflecting restrictions on the role of agents in financial services delivery. Few countries (Egypt, Jordan and Morocco) have also achieved interoperability in mobile payments. Digital payment instruments (credit and debit cards) are still limited in most nonGCC countries (Figure 26). Debit cards, which are more prevalent, are not accepted in ecommerce transactions. Fintech activities are still concentrated in seven countries (UAE, Saudi Arabia, Bahrain, Egypt, Iran, Jordan, and Lebanon) and the innovations are focused more on payments and less on the provision of credits, such as $\mathrm{P} 2 \mathrm{P}$ and crowdfunding. Moreover, most telecoms-led mobile digital wallets that are available in the region offer basic functions, such as person-to-person credit transfer, but they do not yet support online payments. Banks' capacity to assess digital projects also remains limited. 


\section{Figure 26. Digital Payment Infrastructure and Financial Services}

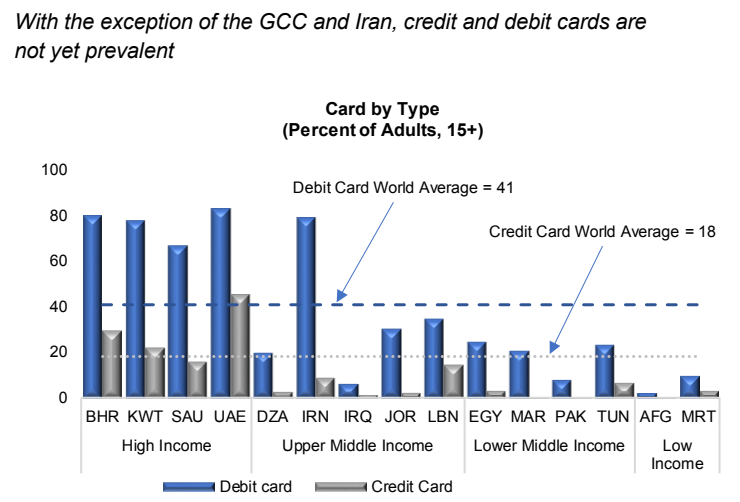

Source: World Bank Findex Database.
Note: Data labels use International Organization for Standardization (ISO) codes.

The infrastructure facilitating access is equally underdeveloped...

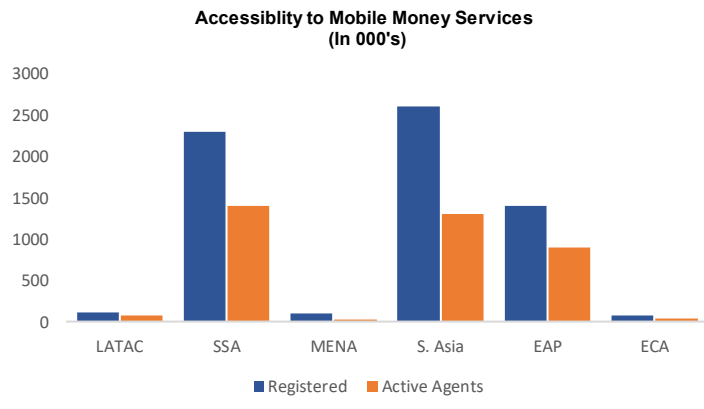

Source: GSMA

But fintech activity remain concentrated in a few countries

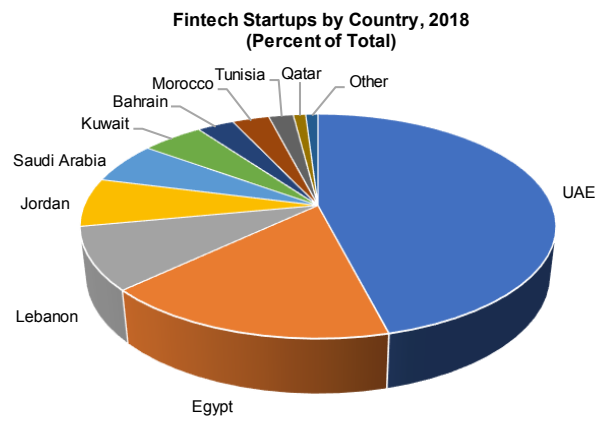

Sources: Magnitt and Abu Dhabi Global Market, MENA Fintech Venture Report.
POS needed for consumers to pay electronically are relatively scarce in several countries

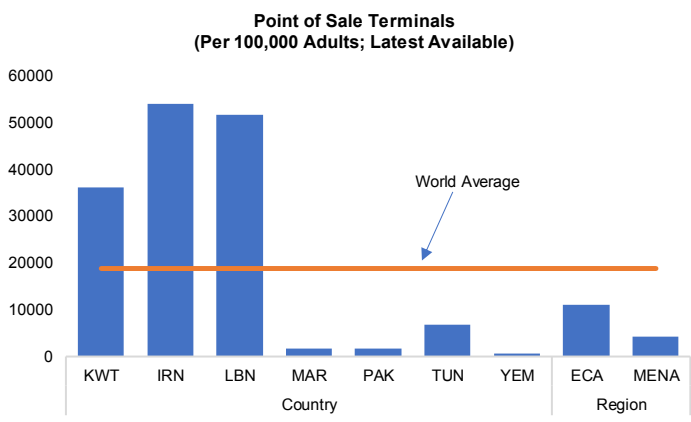

Source: World Bank .

..and few countries have interoperable mobile payment systems.

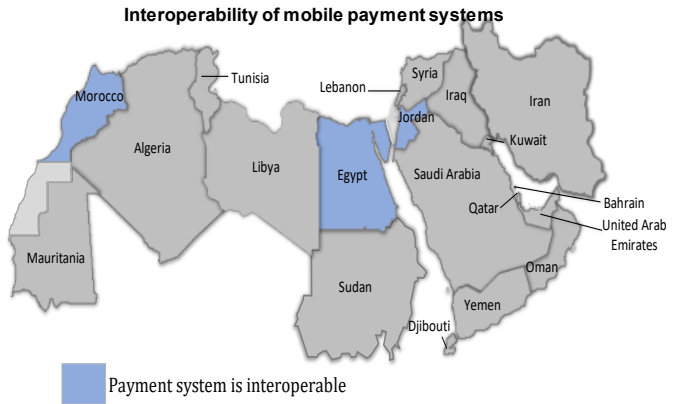

Innovations are focused on payment and much less on lending...

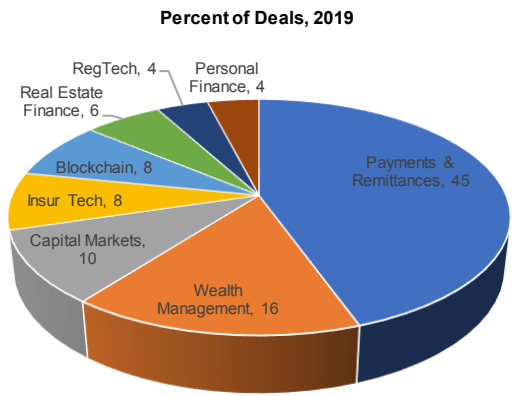


The importance of e-commerce is well recognized in the region, but preconditions are lacking in many countries (Figure 27) ${ }^{24}$ In 2016, the Arab Federation of e-commerce was established to develop the MENA's e-commerce sector. ${ }^{25}$ However, e-commerce logisticsunified address systems, area codes, postal service, land customs - exhibit deficiencies, and this hampers last mile delivery, ${ }^{26}$ causes delays in delivery, and increases dependence on more expensive air-shipments (Fabre et al 2019). Online marketplaces and digital payment instruments are also limited while many SMEs lack the skills to develop effective websites. Outside of the GCC, many countries in MENAP have large shares of unbanked and unconnected populations which limits demand. Legislative measures for e-transactions and cybercrime are largely in place, but less progress has been made with respect to consumer protection and data protection and privacy legislation. Several countries - for example the GCC and Jordan - have launched digital signature services which should help e-commerce to expand.

\section{Figure 27. Factors Constraining E-Commerce Development}

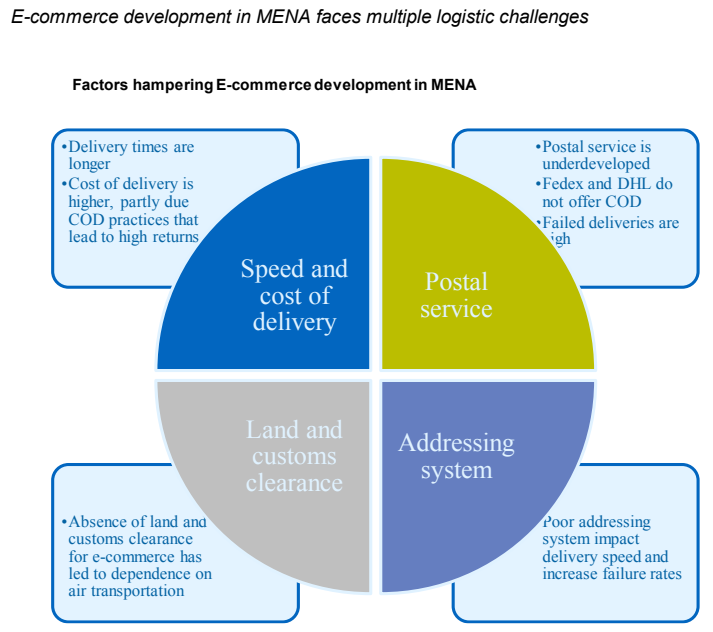

Source: Google and Bain, White Paper 2018

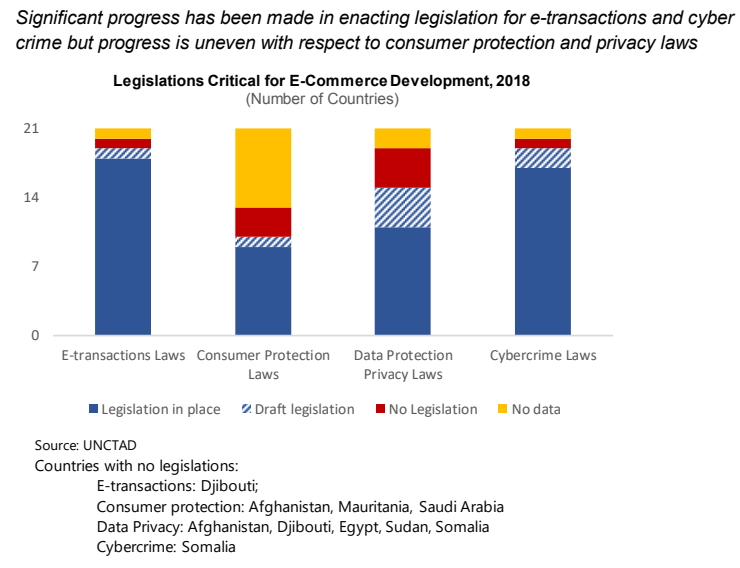

Significant progress has been made in enacting legislation for e-transactions and cyber Legislations Critical for E-Commerce Development, 2018

Digital government or e-government strategies have become more prevalent, but few countries have developed nation-wide digital strategies (McKinsey 2016). At the end of 2018, half the countries ranked very high (Bahrain, UAE) or high (Jordan, Iran, Kuwait, Lebanon, Morocco, Oman, Qatar, Saudi Arabia and Tunisia) on the UN E-government

\footnotetext{
${ }^{24}$ To thrive, E-commerce needs to be supported by high speed internet, logistics and trade facilitation, epayment, e-platforms, skill development, talent, awareness, e-procurement and legal and regulation governing e-transactions, data protection and privacy, consumer protection and cybersecurity.

${ }^{25}$ The Arab Federation represents 14 countries across the broader MENA region. Some countries (Saudi Arabia, Egypt) have also embarked on national strategies to promote e-commerce among SMEs.

${ }^{26}$ Innovative solutions that use GPS functionality to locate customers using their phones are in early stages.
} 
development index. With respect to online provision of government services, seven countries (Bahrain, Kuwait, Oman, Qatar, Saudi Arabia, UAE and Tunisia) rank very high followed by Egypt, Iran, Morocco and Pakistan. While the digitization of government services is a good starting point, thus far few countries (Egypt, Oman) have nation-wide digital strategies (McKinsey 2016). Similarly, few countries (Saudi Arabia) have developed online services that target SMEs. ${ }^{27}$

\section{Demand Side Constraints}

Demand side constraints currently constitute the immediate impediment to the digitalization of SMEs in MENAP. The large digital "usage gap" that is several multiples of the "coverage gap" suggests that constraints to digital adoption go beyond coverage. ${ }^{28}$ In particular, while the coverage gap has significantly declined, the "usage gap" increased before plateauing at an elevated level (Figure 28). Lack of internal capabilities, knowledge gaps in SMEs about suitable digital solutions, high cost of broadband relative to incomes, financial constraints, and limited implementation capacity are some of the factors constraining adoption of digital solutions by SMEs in MENAP. While the MENAP region faces digital skill gaps in general, the scale of SMEs and limited financial resources make it difficult to compete for talent with big corporations and governments that offer higher wages.

\section{Figure 28. ICT Usage Gap}
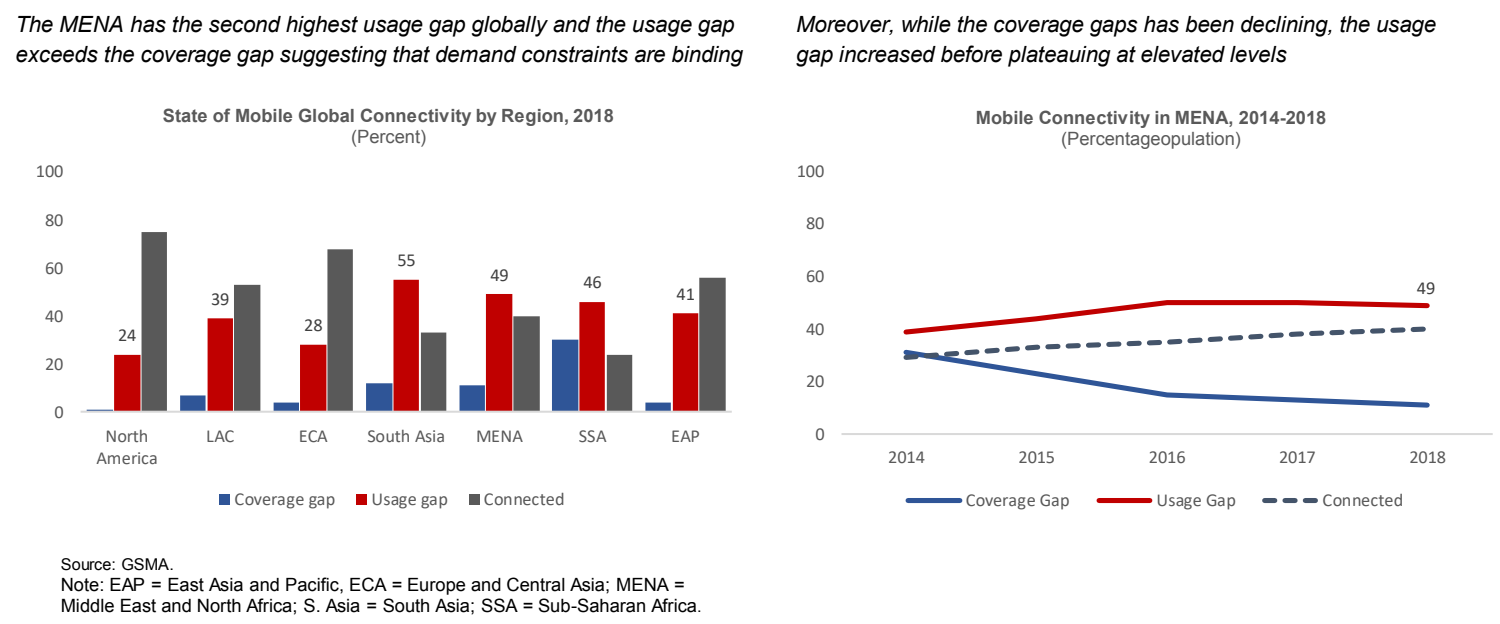

Nource: GSMA. Middle East and North Africa; S. Asia = South Asia; SSA = Sub-Saharan Africa.

The readiness of consumers is another limiting factor. Consumers in many of the non-GCC frontier markets are also not well equipped to adopt digital solutions needed to support

\footnotetext{
${ }^{27}$ Saudi Arabia's digital portal Etimad enables easy access for all SMEs to government tenders, ensure fair competition, increase transparency and greater opportunities.

${ }^{28}$ The "usage gaps" captures the disparity between people who live in areas covered by mobile broadband but who are not using internet.
} 
SMEs' digital transformation. In many lower income countries, half the populations do not have access to affordable quality internet and unconnected persons cannot participate in the digital economy. Ownership of smartphone and other internet-enabled devices is also uneven along income lines with the higher income countries (GCC) exhibiting high penetration rates (Figure 29). The cost of internet-enabled devices has not fallen sufficiently and remains a key barrier to mobile ownership in lower income countries (GSMA 2019).

\section{Figure 29. Consumer Readiness}

The share of internet shoppers in relation to internet users and populations is low for most countries

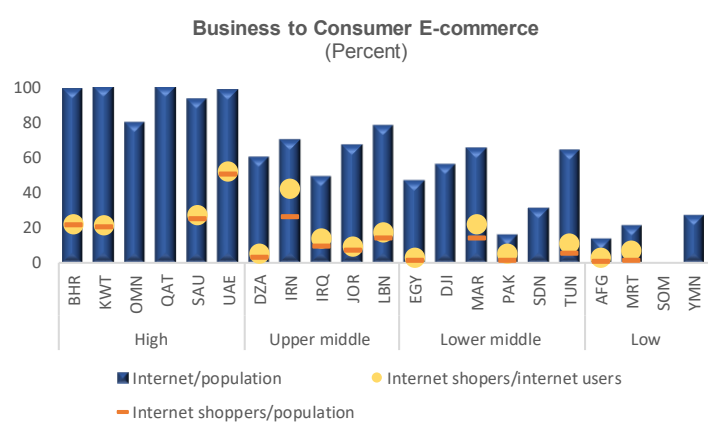

Source: UNCTAD

Higher smartphone penetration in the GCC also facilitate internet usage

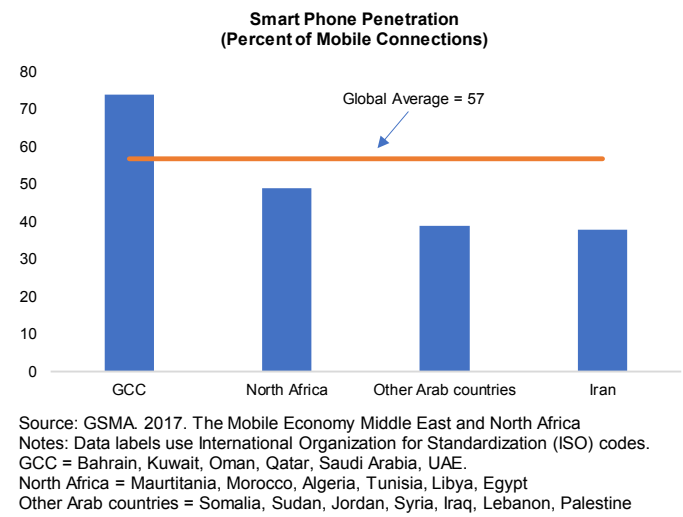

...and usage of mobile money is much lower than many other regions
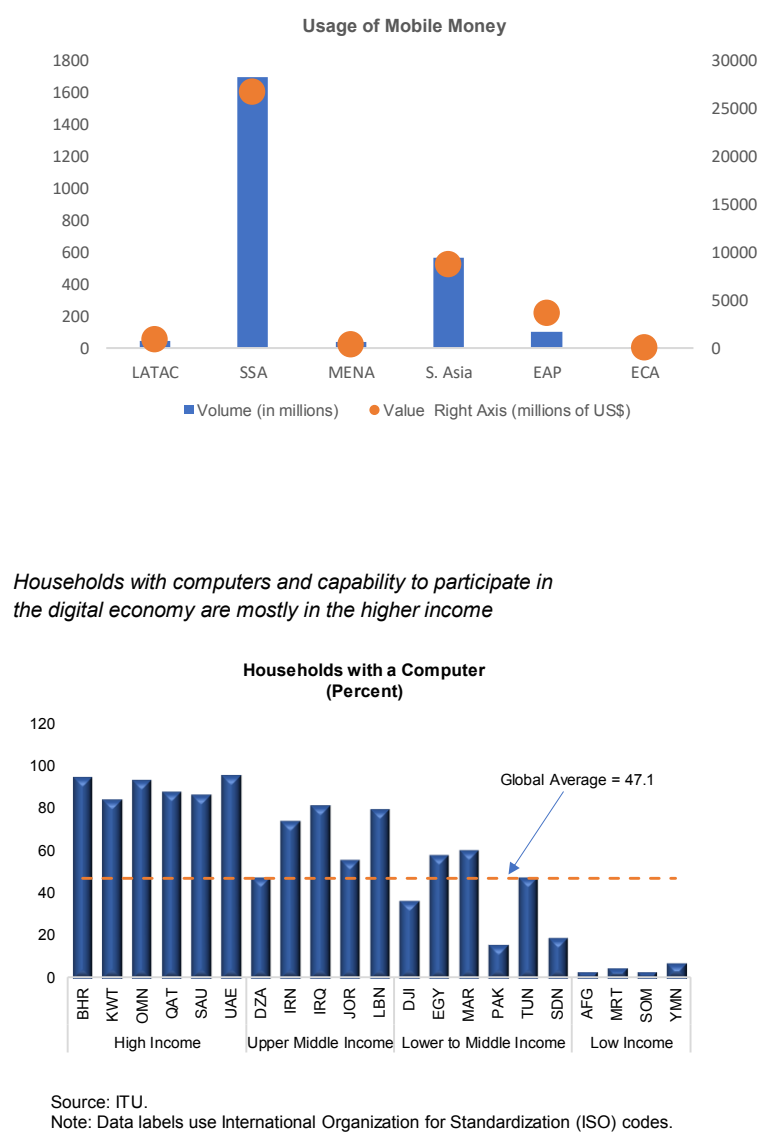

Lack of trust also constrain adoption of digital payments (Figure 30). Consumers still do not trust websites to handle their information and are unaware of their consumer rights. Cash on Delivery (COD) is, therefore, the preferred method of payment even for online purchases. Restrictive regulations that limit non-banks from issuing e-money also constrain adoption and usage of mobile money (Lukonga 2018). 
Figure 30. Payment Methods

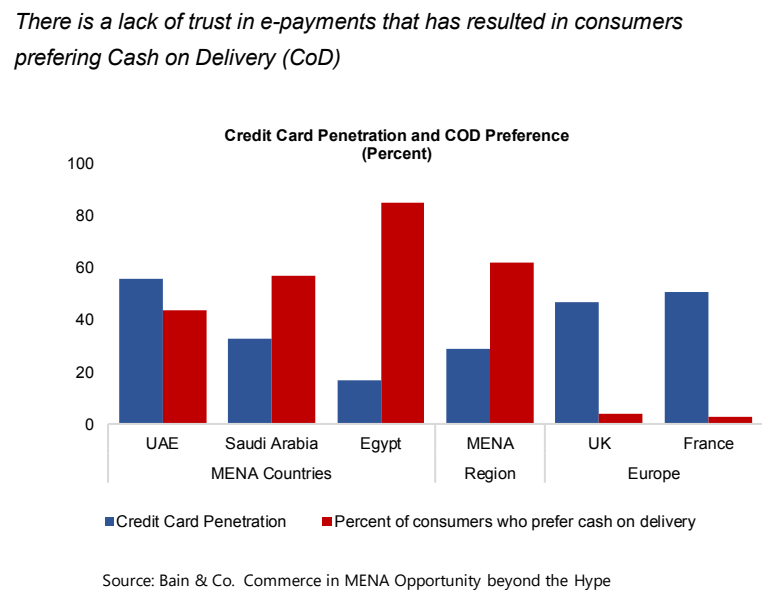

... and outside the GCC and Iran, use of digital payments is limited

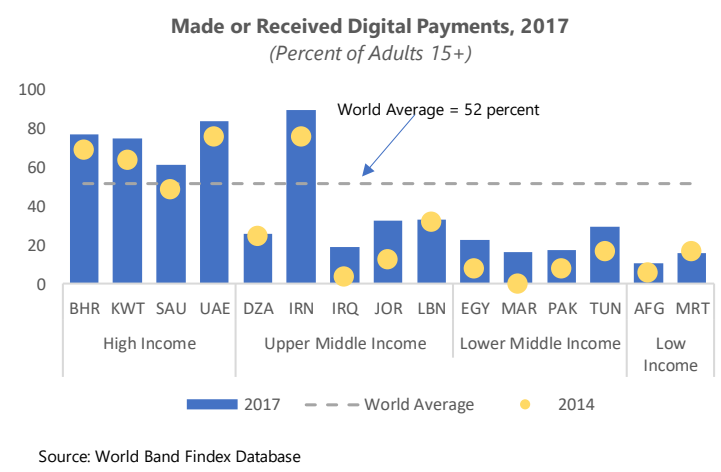

IV. Policy Options to Promote SMEs and InClusive Growth in MENAP

Policies to promote SME growth and employment have not had the envisioned success, thus a fundamental re-thinking of the strategy for developing SMEs is needed. Partial implementation of reforms and idiosyncratic factors contributed to the underperformance, but frictions in the design of SME policies also played important roles. A perpetuation of the same strategy, therefore, cannot yield the needed growth in SMEs and in employment. In a rapidly digitalizing global economy, the growing digital divide will increase inequalities between countries and firms without a digital presence can become marginalized.

Digital technologies promise to be a game changer in boosting the growth of businesses and their resilience to shocks, but technology by itself will not lead to broadly shared prosperity. Transformational visions outlined by some countries are the right path forward but there is need to move from e-government-focused digital initiatives to full digital economy development (McKinsey 2016) and for more countries to create the needed enabling environment to foster digital innovation. Firms will need to embrace agility through digital to address the ever-faster changing business environment. Overall, a well-articulated strategy that addresses supply and demand constraints to digital adoption by businesses complemented by sustained efforts to implement financial sector and the business support reforms is the key to success.

\section{A. An Enabling Environment for Digitalization of SMEs}

Digital ecosystems have developed unevenly across the MENAP region, thus the priorities for countries differ. The GCC has achieved a high level of connectivity and broadband penetration, but scope remains to strengthen other elements of the digital ecosystems for SMEs and develop the frameworks for adoption of cloud technologies and services. For most other countries the connectivity infrastructure remains inadequate, access and usage of 
broadband internet remains a challenge for large segments of the populations, and the digital ecosystem exhibit major gaps, thus the reform agenda is much broader.

Investments in ICT and other digital infrastructures should be a top priority, and universal access to affordable high-speed quality internet a key objective. The GCC have achieved high levels of $4 \mathrm{G}$ coverage and network performance, but could benefit from further investment in fiber networks, cloud computing, IXPs, and data centers, as well as improved spectrum allocation and increased competition. For most other countries, improving access and quality of internet is a priority, and this requires removing barriers to entry and competition across the value chain - eliminating monopoly status over the international gateway, liberalizing the market for building and operating domestic backbone networks, encouraging open access to networks for fixed international and domestic long distance, and allowing competition in end-user connectivity. These measures, along with initiatives related to decreasing costs, are crucial to creating a favorable investment climate and boosting infrastructure rollout.

Educational and labor market reforms should be accelerated and aligned with industry needs to reduce the digital skill gaps. Efforts should focus on increasing the supply of digital skilled staff to enable businesses to fill positions and the labor force to participate in the digital economy. Creation of digital curricula and seamless learning pathways from primary schools to higher education and into employment will be essential (McKinsey 2016). This entails mandating Science, Technology, Engineering and Mathematics (STEM) subjects in school curriculums and providing technical and vocational education and training through public private partnerships. The fast pace of digital evolution also requires that investments in education provide lifelong access to learning opportunities. Easing labor restrictions to facilitate expatriates in highly technical areas can also help reduce the skill gaps in the immediate term.

Digital financials services (DFS) are the life blood for digitalization and require policies that promote innovation policies while mitigating the risks. Banks need to develop expertise in assessing digital projects, but governments can create an enabling environment by ensuring that reforms address the regulatory constraints that impede innovation as well as investments in the payment infrastructures. More specifically:

- Central banks, in collaboration with financial institutions, should strive to have retail digital payment systems that are interoperable and facilitate real time, convenient, safe, and ubiquitous payment services. Improving the cost, speed and reliability of cross border payments would also remove frictions that prevent many small businesses reaching out to customers beyond their borders

- Regulations should facilitate establishment of P2P and crowdfunding platforms, payment gateways, and Points of Sale (PoS) terminals. 
- Regulators should step up oversight activities of digital financial services to fully monitor and ensure safety, efficiency, and reliability of DFS and engage telecom regulators to enhance operational reliability of DFS.

- Collaboration with telecom regulators can help enhance operational reliability of DFS, particularly in remote and rural areas, which may pose operational risks that could adversely affect agent and customer confidence in DFS.

- Regulatory sandboxes can help enhance supervisory communications with market participants, accelerate digital transformation of traditional entities and improve their knowledge of technologies, market development, and application of regulatory and supervisory frameworks. Risks will, however, need to be addressed, including ensuring an even playing field between fully regulated entities and those operating in the sandbox to avoid regulatory arbitrage (Wilson 2019)

Digital government or e-government strategies should go beyond digitization of government services to include national strategies. Digitalizing government services can also help in collection of data for effective policy formulation. Electronic procurement can stimulate the modernization of SMEs and provide incentives for SME use of ICTs and e-commerce.

Other infrastructure gaps will need to be closed. There is a need to address logistics challenges such as inadequate warehouse coverage, scarcity in regional distribution centers, weaknesses in postal services and lack of postal codes as well as limitations in land and customs clearance. As internet requires a reliable supply of electricity, infrastructure gaps in the energy sector, though not discussed in the paper, will need to be addressed.

The large internet "usage gap" indicates that demand constraints are binding, thus policies to promote SMEs' uptake of digital solutions are needed. Gaps in digital skills and know-how call for awareness campaigns on the benefits of digital technologies; promoting relevant content, including in Arabic; providing SMEs with training facilities in ICT; and holding digital literacy programs to enable consumers to participate in the digital revolution while avoiding fraud and costly mistakes. Barriers relating to affordability of ICT services call for policies that encourage competition and a review of how ICT taxation impacts affordability of devices. Trust is also fundamental to SMEs adopting digital technologies, thus coherent strategies for digital security and privacy and online consumer protection are critical. In addition, internet cannot function without electricity, thus ensuring reliability of electricity supply should be an equal priority.

Regulatory and supervisory frameworks warrant review to ensure that they allow the appropriate and safe use of innovative technologies. Investments in ICT and payment infrastructure should be complemented with regulations for e-transactions, consumer protection, and data privacy so as to balance the need for firms to collect and analyze data for innovation and efficiency gains with the concerns about security, privacy, and data governance as well as e-signatures and e-contract laws. Other areas deserving attention are 
electronic signature laws, contract enforcement, insolvency, intellectual property laws, KYC requirements, and cross-border remittances.

The rural-urban digital divide requires government intervention. The digital divide threatens to widen income inequalities and render the policy objective of inclusive growth elusive. National digital strategies should have clear targets to achieve universal affordable highspeed internet, and policies should address the commercial viability of rural telecom infrastructure roll out.

\section{B. Financial Sector and Business Environment Reforms}

For digital benefits to materialize, further reforms are needed in the financial sector and business environment. Five reform areas warrant attention, including deepening the financial sectors, ensuring coherence in policy mix, improving the business environment, strengthening the institutional support framework, and developing SME statistics.

Financial sectors need further development to strengthen financial infrastructures, non-bank financial segments, and capital markets. Further efforts are needed to deepen and broaden the coverage of credit registries and bureaus to include SMEs, to modernize the insolvency regime to avoid criminalizing bankruptcy that occurs as part of normal business operations and reduce the time for resolution and improve recovery rates. There is also a need to enact secured transactions laws for moveable collateral to allow a broader range of collaterals (immovable and movables) with clear priority rankings of claims over collateral supported by electronic registries that make priority interests publicly known. Effective enforcement of collateral in the case of default should also be a priority. Improvements are needed to regulatory frameworks for microfinance, factoring, leasing, corporate bond markets, private equity, and venture capital. Regulators should also ensure comparable supervisory approaches across financial institutions, albeit on a proportional basis including in prudential frameworks and access to infrastructure, including credit registries and credit bureaus.

Macro and regulatory policies need careful calibration to ensure a coherent policy mix and minimize unintended consequences. Interest rate caps can discourage bank lending to SMEs since it limits the ability to price risk appropriately, thus a relaxation of interest rate caps is needed. Policies to promote bank lending to SMEs should be balanced to ensure that financial inclusion objectives are not achieved at the cost of financial stability. Public sector wages should be reviewed from the perspective of competitiveness. Government borrowing to finance fiscal deficits should take account of the risks of crowding out the private sector, especially SMEs.

The institutional support framework for SMEs needs streamlining and to be refocused. There is a need to address fragmentation and overlapping mandates, improve coordination and establish a formal definition of SMEs that is consistently applied. SME support policies should tilt from providing soft financing toward enabling SMEs to qualify for financing by enhancing their managerial capabilities. There is a need to institutionalize programs such as 
business incubators to assist entrepreneurs effect their ideas and raise the level of patentable innovation. Regulatory impact studies should be undertaken at regular intervals and special incentives should be given to SME scale ups or "gazelles" that have potential to create quality job opportunities.

More systematic and regular compilation of SME data is needed to facilitate policy formulation that is evidence based. This requires information on the number of firmscharacteristics of the SMEs by size, gender, age and education, their sectoral distribution, their contribution to output and employment, new entries and exits, gender participation, and bank credit to SMEs and SMEs share of NPLs. 


\section{Appendix 1. Digital Technologies and the Potential Benefits they Present}

\begin{tabular}{|c|c|c|}
\hline & Descriptions & Benefits for SMEs \\
\hline $\begin{array}{l}\text { Internet of } \\
\text { Things }\end{array}$ & $\begin{array}{l}\text { Enables a host of new business models, } \\
\text { applications and services based on data collected } \\
\text { from divices and objects. For instance, a GPS } \\
\text { embeded in a telephone can track the users } \\
\text { location }\end{array}$ & $\begin{array}{l}\text { - Better interaction with clients } \\
\text { - Improved efficiency and reduction in operational } \\
\text { costs } \\
\text { - In retail stores: Allows SMEs to provide tailored } \\
\text { products } \\
\text { - In production: Anticipate stock replacement } \\
\text { - In Logistics: Calculate better delivery routes and } \\
\text { improves customer experience }\end{array}$ \\
\hline $\begin{array}{l}\text { Cloud } \\
\text { Computing }\end{array}$ & $\begin{array}{l}\text { Cloud computing is the delivery of computing } \\
\text { services like servers, storages and more over the } \\
\text { internet. Cloud providers charge for cloud } \\
\text { services based on usage. The services include } \\
\text { Infrastructure as a Service (IaaS), Platform as a } \\
\text { Service (PaaS), Software as a Service (SaaS) or } \\
\text { storage, data base, etc. }\end{array}$ & $\begin{array}{l}\text { - Most SMEs opt for SaaS or IT services from niche } \\
\text { service providers which helps reduce cost of } \\
\text { digitalization, partially addresses the knowledge } \\
\text { gap and ensures cost effective security. } \\
\text { - Reduces upfront ICT infrastructure costs, and } \\
\text { software easier to install, maintain and update } \\
\text { - Resources can be used and priced in a scalable } \\
\text { and adaptable manner, and reduces piracy risk }\end{array}$ \\
\hline Analytics & $\begin{array}{l}\text { Analysis of data characterised by high volume, } \\
\text { velocity and variety of sources, such as market } \\
\text { transactions, data retrieved from sensors or } \\
\text { social media content }\end{array}$ & $\begin{array}{l}\text { - } \text { Effective use of data for business decisions } \\
\text { ability to compete with larger firms } \\
\text { - Reduced costs and increased productivity } \\
\text { - Enhanced design of marketing projects } \\
\text { - Ability to forsee and identify trends }\end{array}$ \\
\hline $\begin{array}{c}\text { Artificial } \\
\text { Intelligence }\end{array}$ & $\begin{array}{l}\text { AI is the ability of machines and systems to } \\
\text { acquire and apply knowledge, including by } \\
\text { performing a broad variety of cognitive tasks, } \\
\text { such as sensing, processing language, pattern } \\
\text { recognition, learning and making decisions and } \\
\text { predictions. Machine Learning is key to the } \\
\text { development of AI. }\end{array}$ & $\begin{array}{l}\text { - Fewer employee expenses, as robots can } \\
\text { execute several repetitive tasks } \\
\text { - Greater efficiency } \\
\text { - Reduced errors related to the collection and } \\
\text { analysis of vast amounts of data }\end{array}$ \\
\hline Blockchain & $\begin{array}{l}\text { Enables applications to authenticate ownership } \\
\text { and carry out secure transactions for a variety of } \\
\text { asset typs. It is a ledger or spreadsheet that is } \\
\text { maintained and stored across a network of } \\
\text { computers. The network regularly updates the } \\
\text { database in every place it exists, so that all copies } \\
\text { are identical }\end{array}$ & $\begin{array}{l}\text { - Provides full transparency, allowing buyers } \\
\text { and sellers to inquire into the original source } \\
\text { of information } \\
\text { - Smaller businesses can obtain more types of } \\
\text { trusted information at lower cost } \\
\text { - Has been effectively applied in real estate to } \\
\text { provide reliable collateral registries }\end{array}$ \\
\hline
\end{tabular}

Source: OECD Idea Factorv. Harnessina Diaital Technoloaies for Entrebrensures and SMEs. 2019 


\section{References}

Accenture 2016. Accenture Technology Vision 2016. Building a Digital Middle East

Bricker, Annie. 2019. Filling the MENA IT Skills Gap. CIO July 1, 2019

Deloitte. 2014. Technology, Media \& Telecommunications predictions 2014 Middle East

EY. 2015. How will the GCC close the skills gap? Ernst and Young.

Galviz, Jaime. 2020. "Mind the gap: the region's digital-skills shortage... and what to do about it". https://wired.me/technology/microsoft-digital-jobs-middle-east/

Fabre, Cyrille, Malauzat Anne-Laure, Sarkis Charbel, Dhall Tanmay, and Ghorra Josette. 2019. E-Commerce in MENA. Opportunity Beyond Hype. Google and Bain and Company White Paper.

GSMA. 2019. The State of Mobile Internet Connectivity. 2019 GSM Association. https://www.gsma.com/mobilefordevelopment/

IFC 2017. MSME Finance Gap, SME Finance Forum, World Bank.

IMF. 2019. Fintech, The Experience so Far. Bali Fintech Agenda. International Monetary Fund.

Lukonga, Inutu. 2018. Fintech, Inclusive Growth and Cyber Risks. IMF Working Paper. $\mathrm{WP} / 18 / 201$

Lukonga, Inutu. 2020. Harnessing Digital Technologies to Promote SMEs in the MENAP Region. Forthcoming IMF working paper.

Magnit. 2019. MENA Venture Investment Report.

McKinsey \& Company. 2016. Digital Middle East: Transforming the region into a leading digital economy October 2016. Tarek Elmasry, Enrico Benni, Jigar Patel, Jan Peter aus dem Moore

OECD. 2017. Entrepreneurship at a Glance. OECD Publishing, Paris.

OECD 2019a. Vectors of Digital Transformation. www.oecd.org/going-digital.

OECD 2019b. Harnessing Digital Technologies for Entrepreneurs and SMEs. http://www.oecd.org/mena/competitiveness/MENA-SME-idea-factory-flyertechnology.pdf 
PwC. 2017. Empowering the GCC digital workforce Building adaptable skills in the digital era. http://www.strategyand.pwc.com/me

Saleem Q. 2017. Overcoming Constraints to SME Development in MENA Countries and Enhancing Access to Finance. World Bank, IFC.

Sharekh Alanoud A1. 2018. SME Funds as a Vehicle of Economic Reform in Kuwait and the GCC. Center for the Middle East. Carnegie.

WAMDA. 2016. Access to Talent for MENA's entrepreneurs. WAMDA research lab in collaboration with IFC. Beirut Digital District.

Wilson, Christopher and Morozova Anastasiia. 2019. A Supervisor's Guide to Regulatory Sandboxes. MCM Policy Position Note.

World Bank. 2014. Broadband Networks in the Middle East and North Africa, Accelerating High-Speed Internet Access. Directions in Development. Communication and Information Technologies by Gelvanovska, Natalija, Rogy Michel, and Rossotto Carlo Maria.

World Bank. 2016. Digital Dividends. World Development Report. Background paper on Exploring the Relationship Between Broadband and Economic Growth by Michael Minges. ictData.org

World Bank. 2017. Islamic Banking Opportunities Across Small and Medium Enterprises in MENA. IFC

World Bank. 2018. A New Economy for the Middle East and North Africa. MENA Economic Monitor.

World Bank. 2019. Doing Business 2019. World Bank Group. Washington DC.

World Economic Forum (WEF). 2019. Network Readiness Index.

World Economic Forum (WEF). 2017. The Future of Jobs and Skills in the Middle East and North Africa. Preparing the Region for the Fourth Industrial Revolution

World Economic Forum (WEF). 2016. Executive Opinion Survey.

World Trade Organization (WTO). 2019. Global Value Chain Development Report. Chapter 6. The Digital Economy, GVCs and SMEs by Emmanuelle Ganne and Kathyrn Lundquist 